الروئة التكاملية لمهام الإرشاد الزراعي و التوجيه المائي

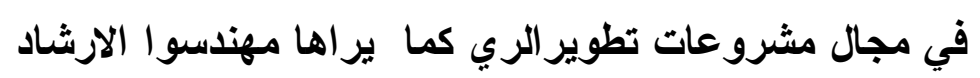

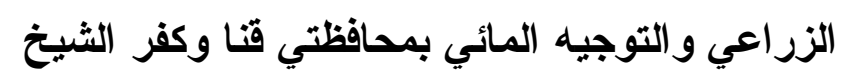

شكري محمد بدران ، احمد حسين يوسف ، وحيد محمد عبد الصادق

معهد بحوث الارشاد الزراعي والتنمية الريفية - مركز البحوث الزراعية - جيزة

المستخلص

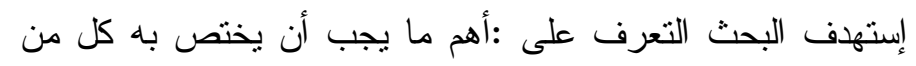

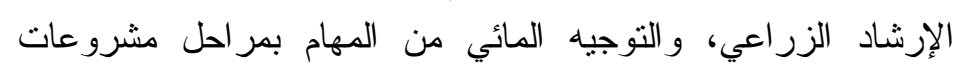

تطوير الري ، و إمكانية قيام العلاقة التكاملية بينهما، و المشكلات التئي الزئي

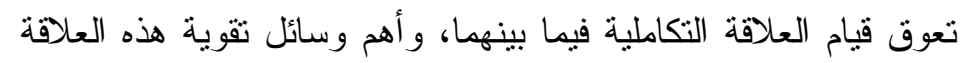

$$
\text { التكاملية بينها في هذا المجال. }
$$

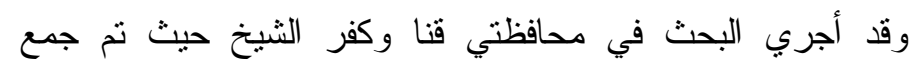

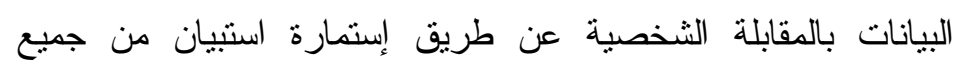

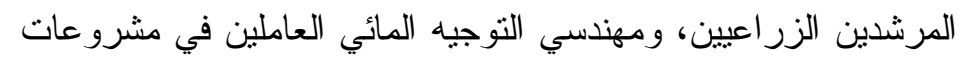

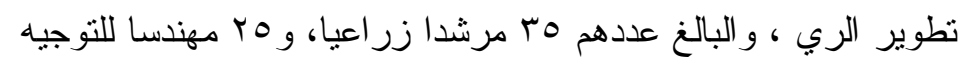

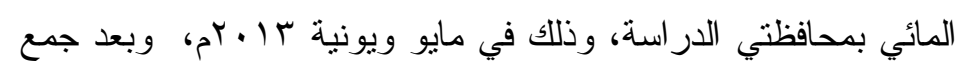

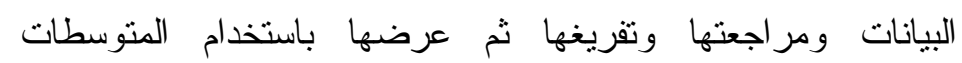

$$
\text { و العرض الجدولي بالتكر ار ات و النسب المئوية. }
$$

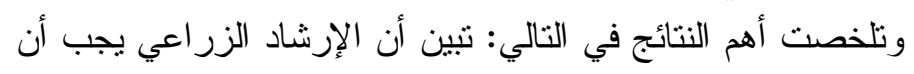

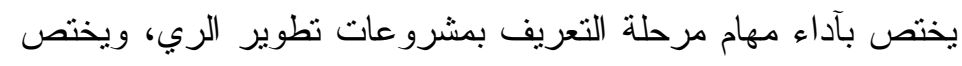

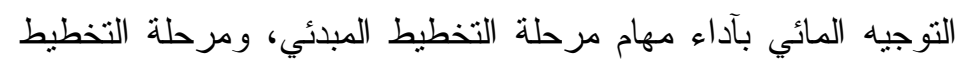

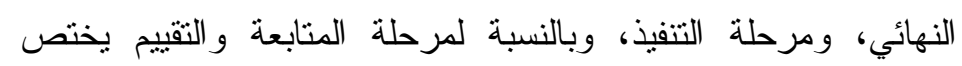
التوجيه المائي بآداء مهام معينة ويختص الإرشاد الزر اعي بآداء مهام

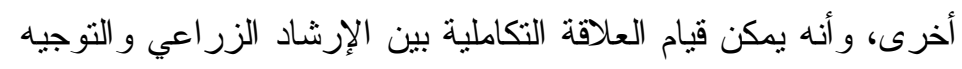

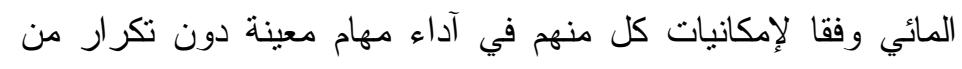

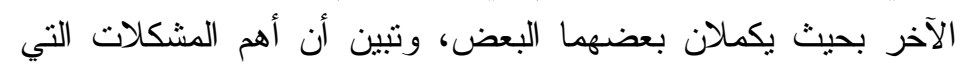

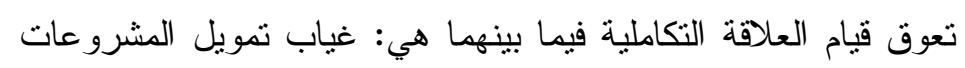
المشتركة، وغياب التدريب، وأن أهم وسائل نقوية العلاقة التكاملية

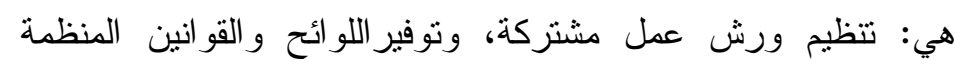
للعمل المشترك. لفظم ورش.

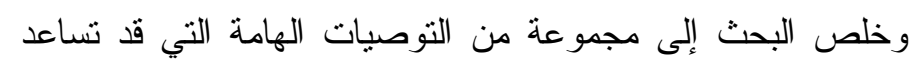

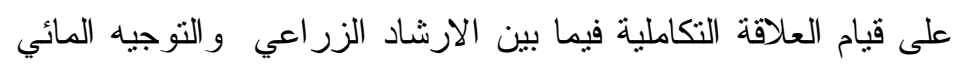
مما قد بساعد على توفير الوقت و الجهد و المال. 


\section{المقدمة و المشكلة البحثية}

تتطلب عملية التتمية المتو اصلة زيادة الناتج المحلى بصفه عامة، و الناتج الزر اعى بصـفة

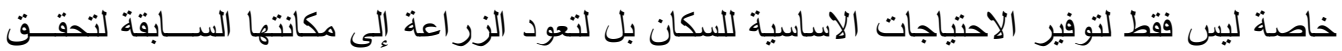

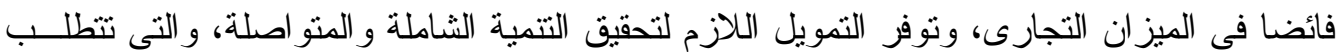
استثمار ات ضخمة لمو اجهة الاحتياجات المتز ايدة للسكان، وتتطلب

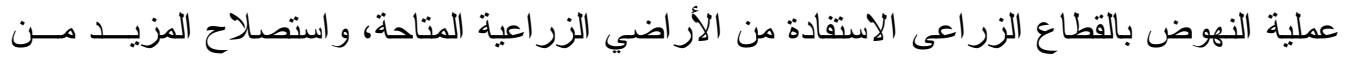

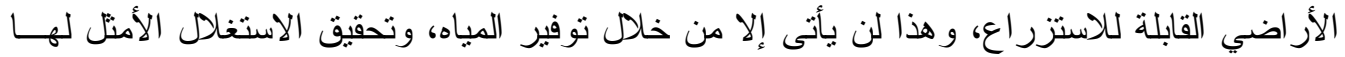

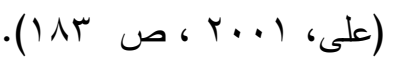

و إحتلت قضية ندرة المو ارد المائية فى مصر بؤرة الاهتمام فى السنوات الأخيرة التى تسبق بداية القرن الواحد و العشرين، فموارد مصر من المياه العذبة من مياه النيل محددة بنحو 00.0 مليار

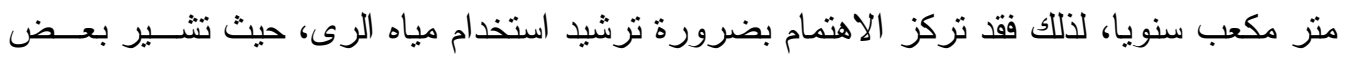

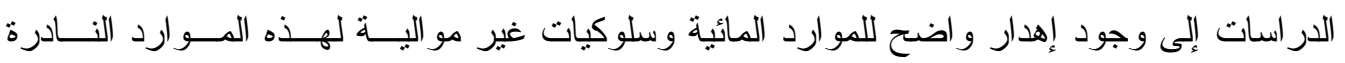

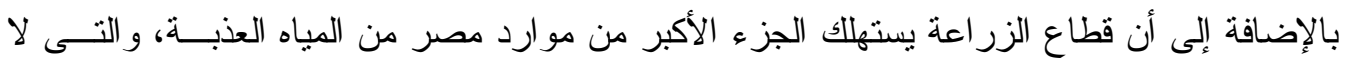

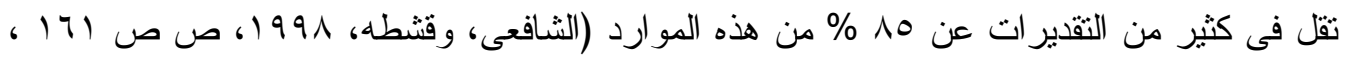

و تستهلك الزر اعة النصيب الأكبر من إجمالي الموارد المائية المتاحــة، و أن نظــام الــرى

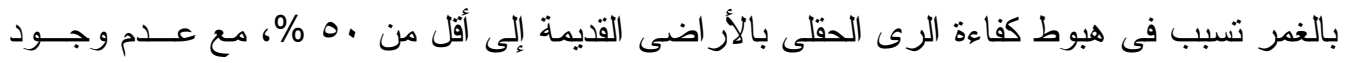

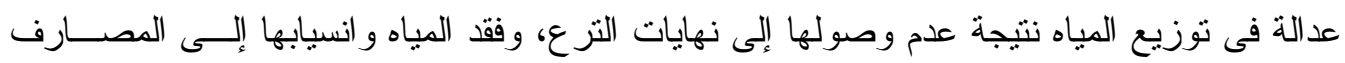

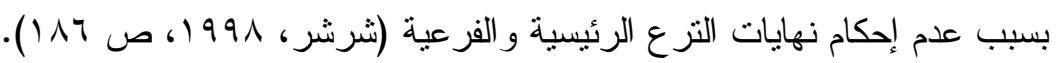

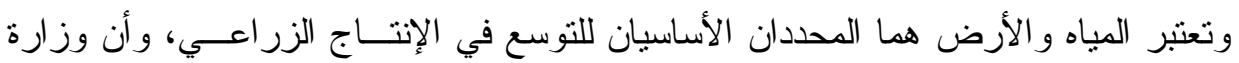

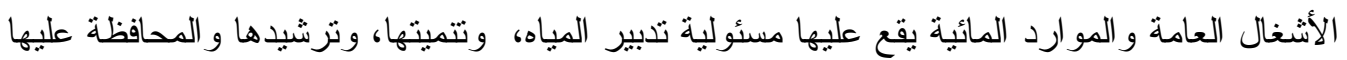

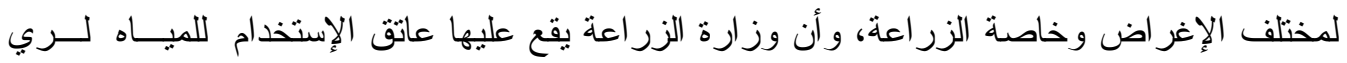

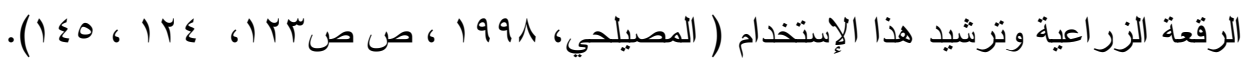

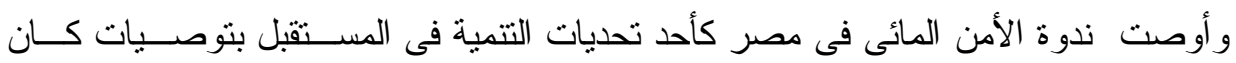

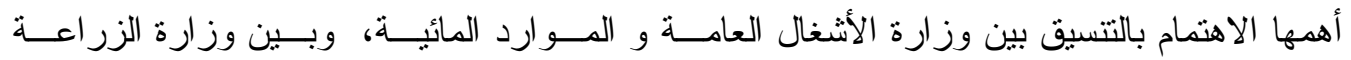

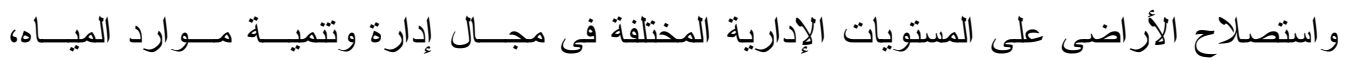

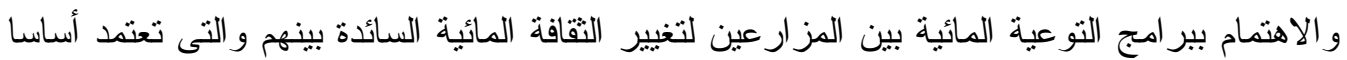

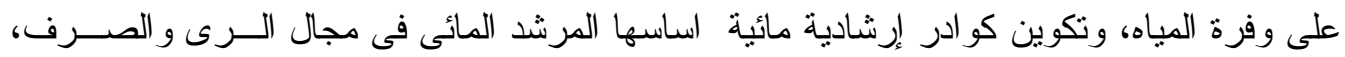

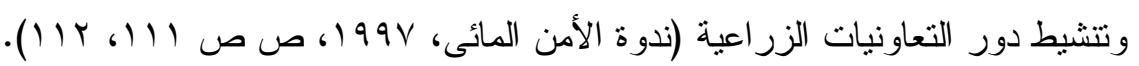

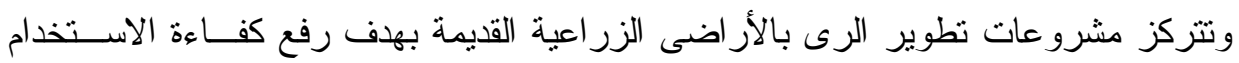

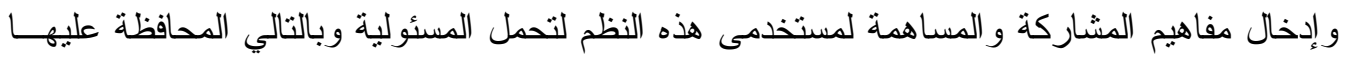
و الحد من فو اقدها المختلفة وذلك بالتوسع فى استخدام وسائل الرى غير التقليدية عن طريق الاحسـلد

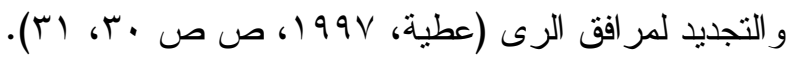


و يحتاج استخدام المياه فى الأر اضى القديمة إلى جهود كبيرة لتغيير سلوكيات الــزر اع غيـر

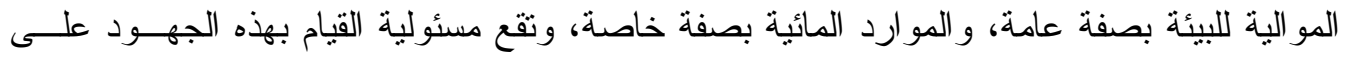

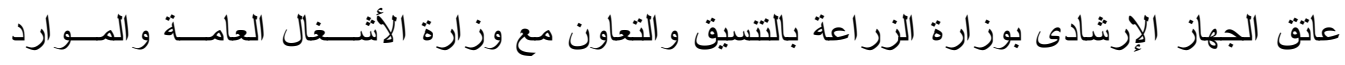

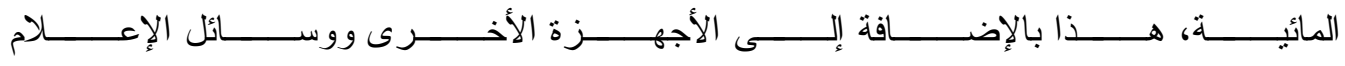

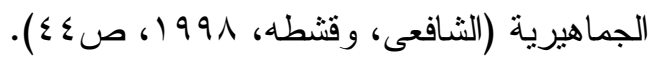

ويقوم جهاز الإرشاد الزر اعي بنوعية الزراع وتعليمهم الأساليب التكنولوجية الحديثة ومحاولة

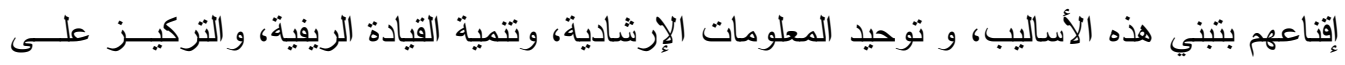

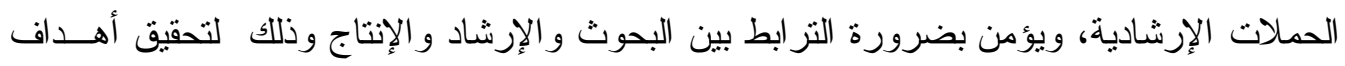

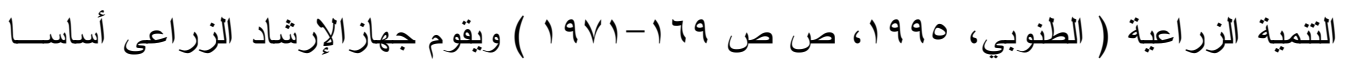

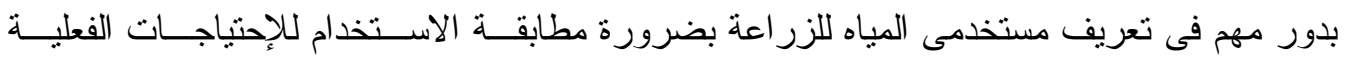

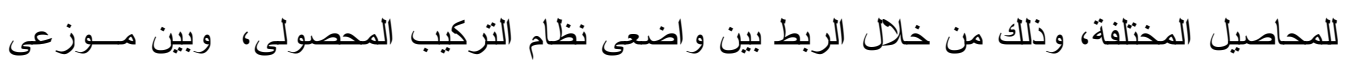

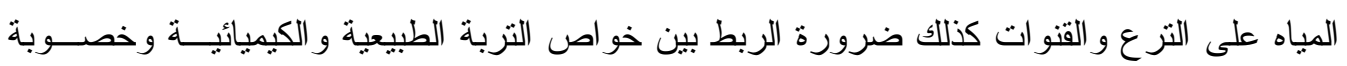

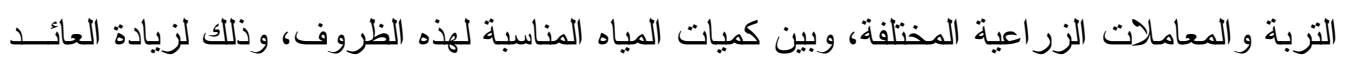

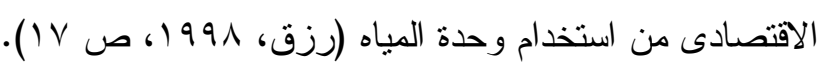

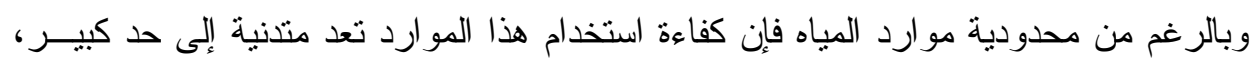

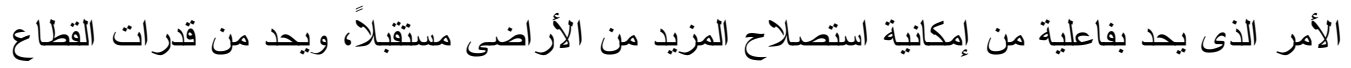
الزر اعى على احراز معدلات عالية للنمو بالإضافة إلى الانخفاض الو اضتح فى كفاءة استخدام الميــاه

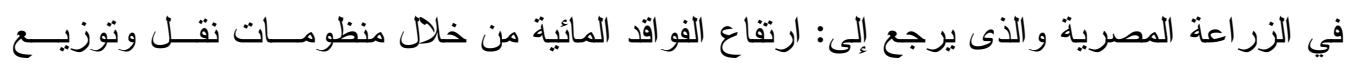

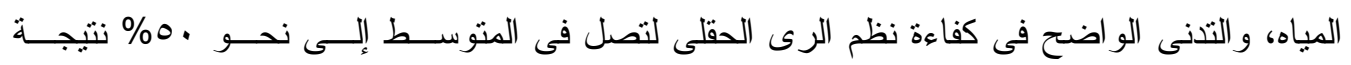

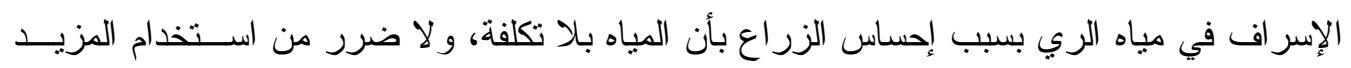

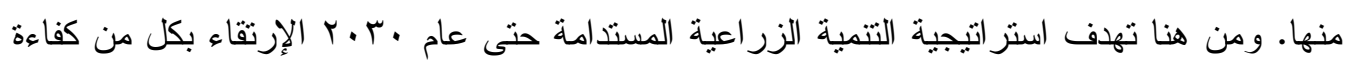

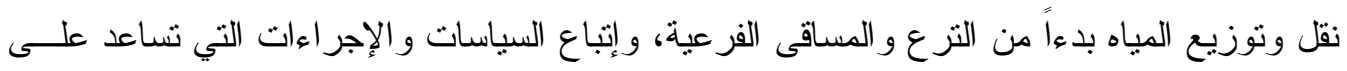

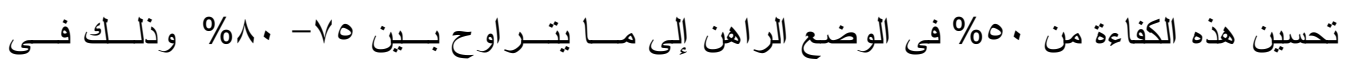

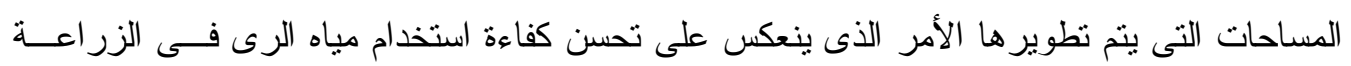

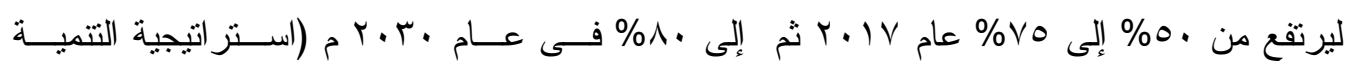

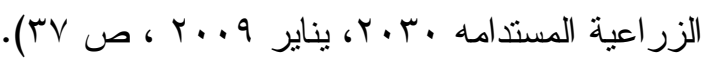

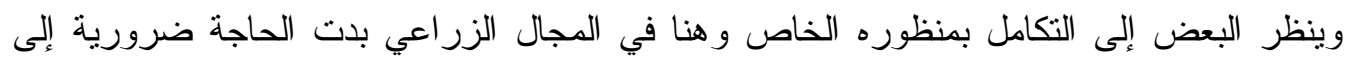

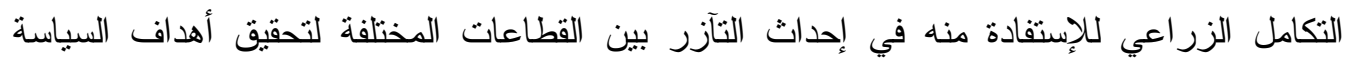
الزر اعية. ويعني درجة ارتباط الوحدات المختلفة في النظام الاجتماعي من خلال قنو ات الاتصال بين

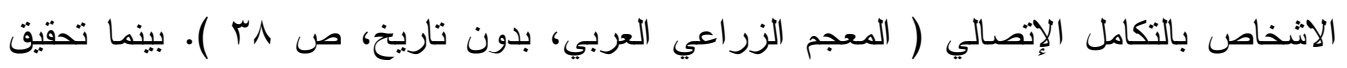

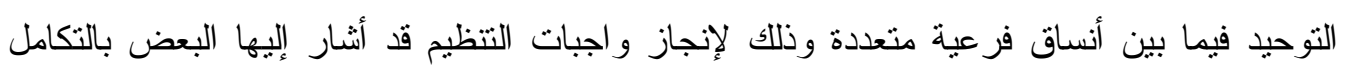




\section{المشكلة البحثية}

على الرغم من الدور الهام لقطاع التوجيه المائى بوزارة الموارد المائية و الري، و الدور الهام

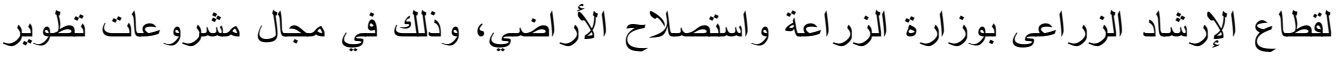

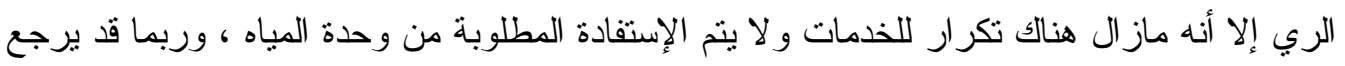
ذللك إلى غياب و عدم تحقيق كثير من الأهداف المنشودة من مشروعات نطوير الري.

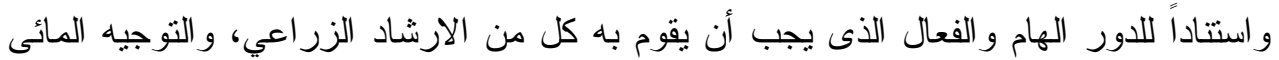
فى مجال مشروعات تطوير الرى فإن هذا البحث يعد محاولة للإجابة على بعض التساؤلات البحثية التالية: ما هي أهم ما يجب أن يختص به كل قطاع من الإرشاد الزراعي، و التوجيه المائي من المهام

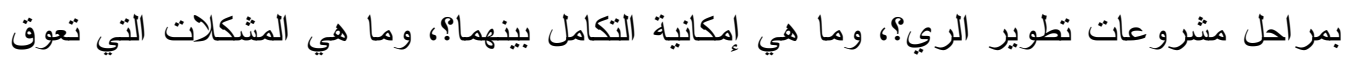
التكامل فيما بينهما؟، وماهي أهم وسائل تقوية التكامل بينهما في هذا المجال؟ لرئ

\section{أهد (اف البحث}

1 - التعرف على أهم ما يجب أن يختص به كل من الإرشاد الزر اعي، و التوجيه المائي والجهـات

$$
\text { الاخرى من المهام }
$$

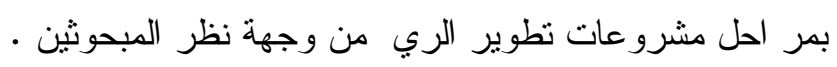

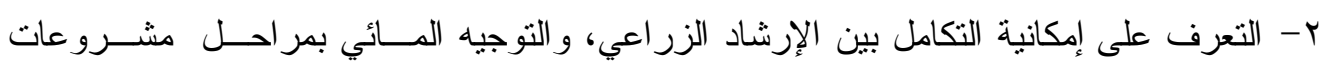
تطوير الري من وجهة نظر المبحوثين. r- التعرف على أهم المشكلات النى تعوق قيام العلاقة التكاملية بين الإرشاد الزر اعى، و التوجيه المائى في مشروعات تطوير الري من وجهة نظر المبحوثين.

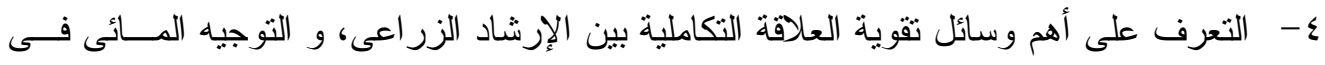
مجال مشرو عات تطوير الرى من وجهة نظر المبحوثين.

\section{التعريفات الإجرائية}

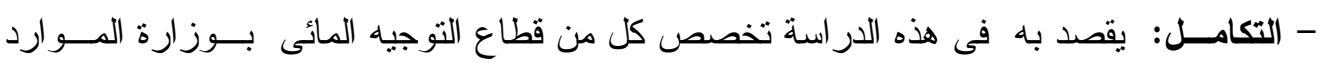

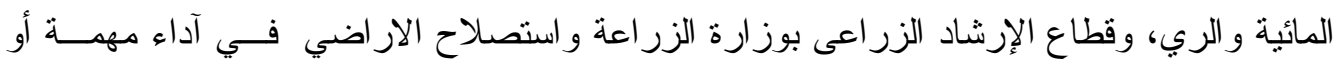

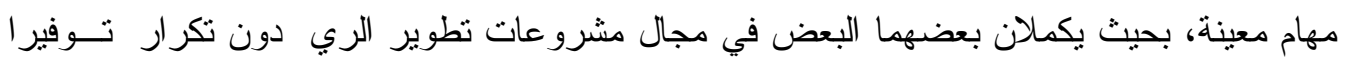

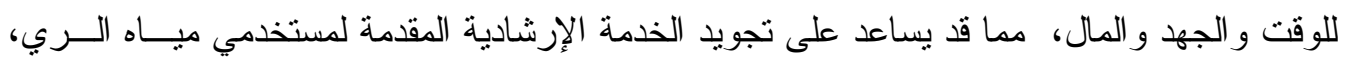
وتحقيق الهدف من مشروعات تطوير الري في ظل ندرة الموارد المائية .

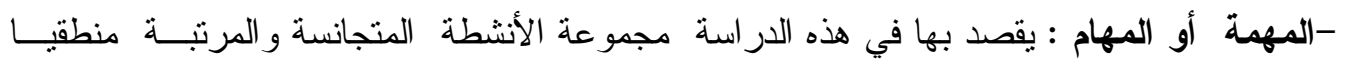

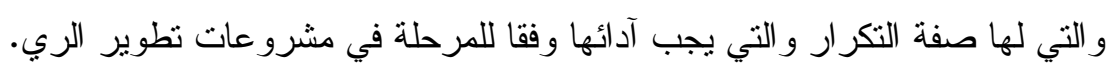

\section{الطريقة البحثية}

المجال الجغر افي: تم اختيار محافظتى قنا وكفر الثيخ لإجر اء هذا البحث لأنهما من المحافظات التى

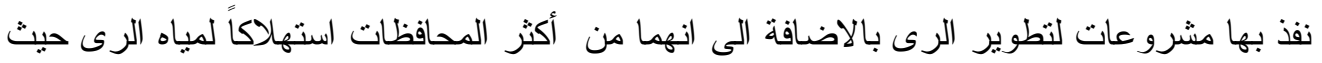

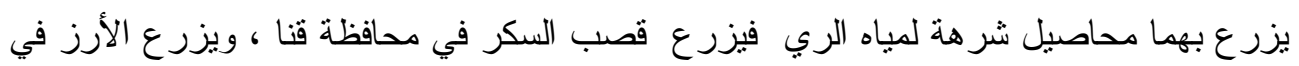

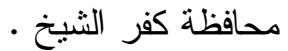


المجال البشري: نم إجراء هذا البحث على شاملة المرشدين الزر اعبين العاملين في مشروعات

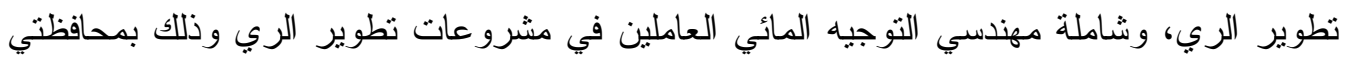

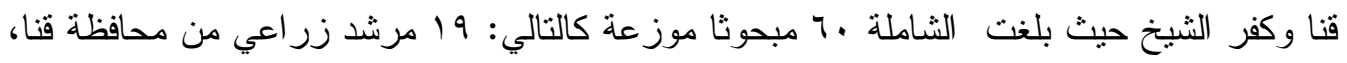

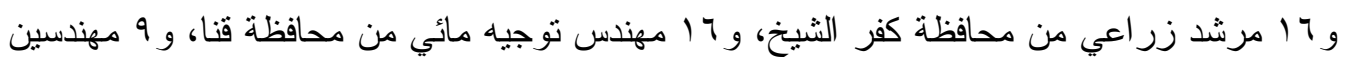
توجيه مائي من محافظة كفر الثيخ. المجال الزمني: جمعت البيانات الميدانية لهذا البحث باستخدام استمارة استبيان اعدت لهذا الغرض،

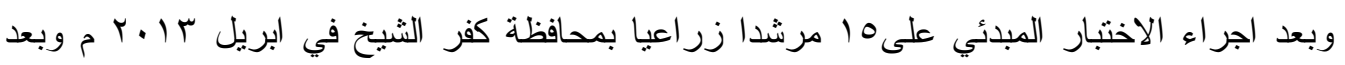

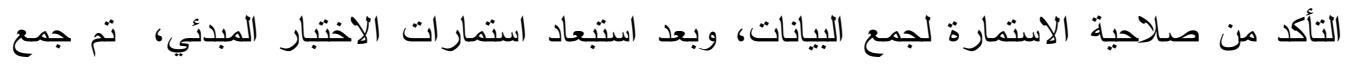

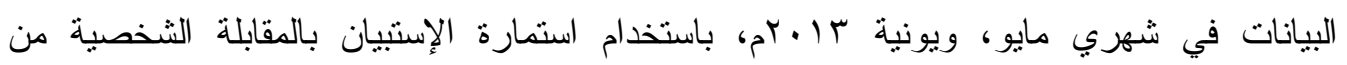

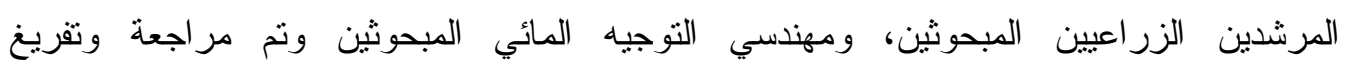

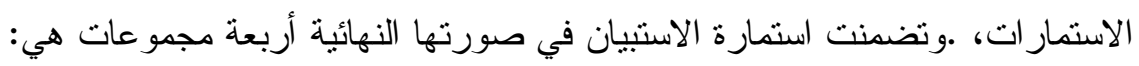
الأولى: المتغير ات الثخصية و المهنية للمبحوثين:

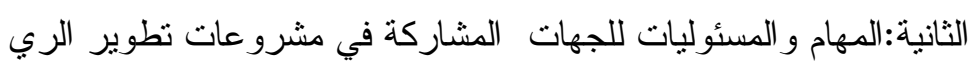
الثالثة: المشكلات التي تعوق قيام العلاقة التكاملية بين الارشاد الزراعي اعي و التوجيه المائي في مجال مشروعات تطوير الري الر ابعة: وسائل تقوية العلاقة التكاملية بين الارشاد الزراعي والتوجيه المائي في مجال مشروعات تطوير الري.

معالجة البياتات: المجموعة الأولى: المتفيرات الثخصية والمهنية للمبحوثين وتتضمن التالي:

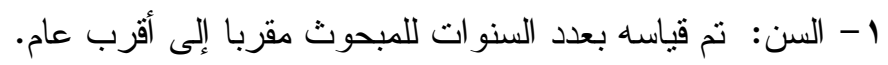

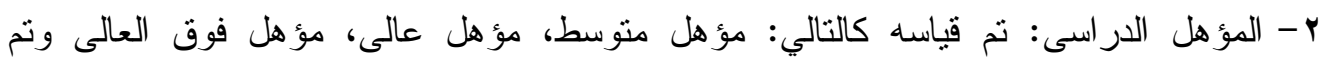

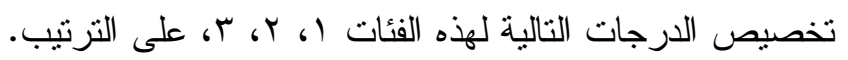

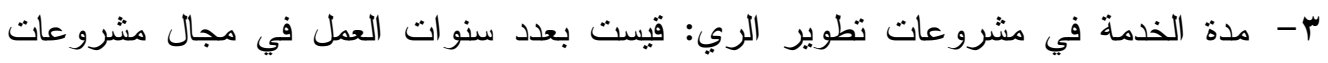

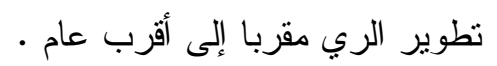
ـ - التذريب على عمليات نطوير الرى: قيست كالتالي: تدرب ، لم يتدرب ون ونم تخصيص لها الدرجات التالية: (، صفر على على التزتيب. 0- عدد الدورات التدرييية التى حصل عليها المتدرب في تطوير الري: قيست بعدد الدورات التي لتربي حصل عليها المتدرب. المجموعة الثانية: المهام والمسئوليات للجهات المشاركة في مشروعات تطوير الري: تم عرض

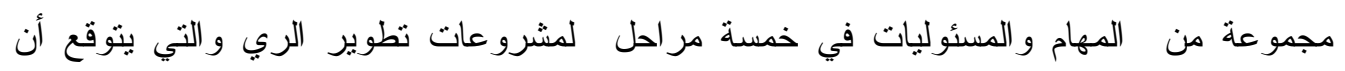

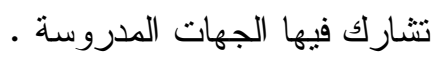
( جمعت وقنتت هذه المهام و المسئوليات من آراء الخبر اء و الباحثين في مجال تطوير الري ) وحسبت النسبة المئوية لإختبار ات المبحوثين للمهام بمشروع تطوير الري كالتالي:

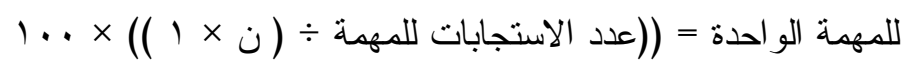


أما بالنسبة لمهام المرحلة الو احدة = ( ( مجموع الاستجابات لكل مهام المرحلة ( ن × عدد مهام

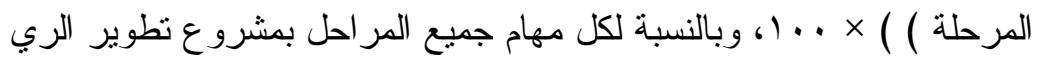

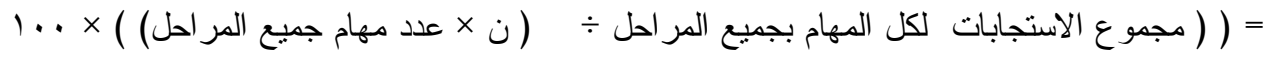
المجموعة الثالثة: المشكلات التي تعوق قيام العلاقة التكاملية بين الارشاد الزراعي والتوجيه المائي في مجال مشروعات تطوير الري: تم عرض مجموعة من المشكلات التي يحتمل أن تعوق قيام العلاقة التكاملية بين الإرشاد الزراعي، و التوجيه المائي وتركت هذه المشكلات مفتوحة لإمكان

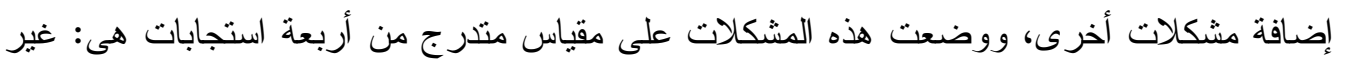

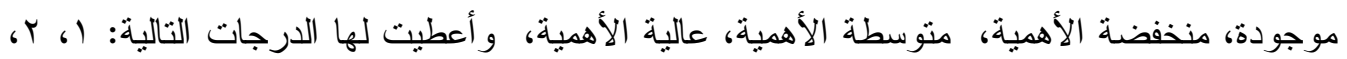
r، ؛ على الترنيب، (جمعت وقنتت هذه المشكلات من آراء الباحثين والخبر اء في مجال تطوير الري ) وتم ترنيب هذه المشكلات وفقا للمتوسط النسبي لدرجة الاهمية للمشكلة كالتالي: الدجة المتوسطة = (غير موجودة ×1 + منخفضة الأهمية ×r + متوسطة الأهمية ×r + عالية الأهمية × ع) ؛ حجم العينة. المتوسط النسبي \% = ( الدرجة المتوسطة ٪ أكبر درجة في المقياس) × . 1. المجموعة الرابعة: وسائل تقوية العلاقة التكاملية بين الارشاد الزراعي والتوجيه المائي في مجال مشروعات تطوير الري: تم عرض مجموعة من الوسائل التي يحتمل أن تقوي العلاقة التكاملية بين

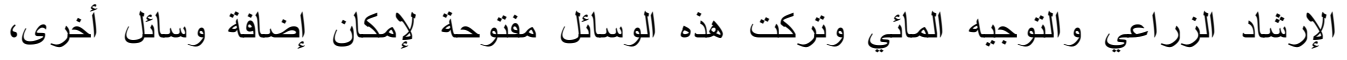

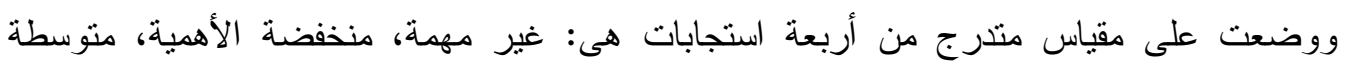

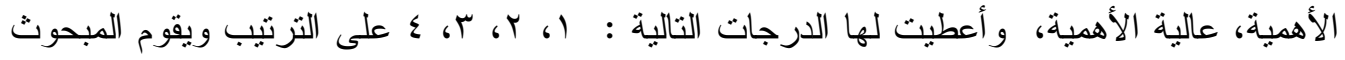
بتحديد درجة أهمية كل وسيلة من هذه الوسائل على هذا المقياس وته ونت ترنيبها ترنيبا تتازليا وفقا للمتوسط النسبي لدرجة الأهمية للوسيلة.

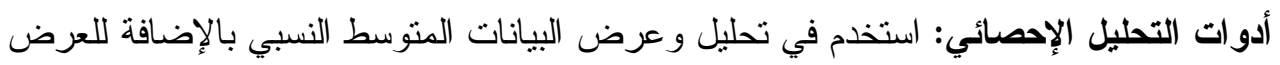
الجدولي بالتكر ار ات و النسب المئوية. المتغيرات الثخصية و المهنية للمبحوثين: أ - المرشدين الزراعيين المبحوثين:

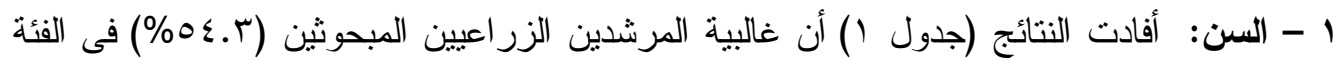

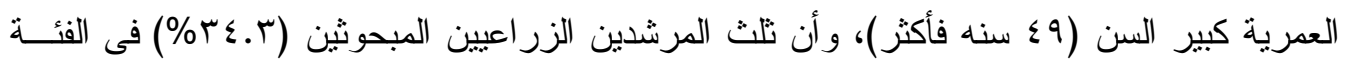

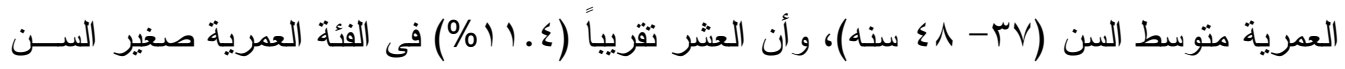

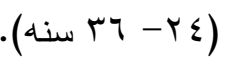

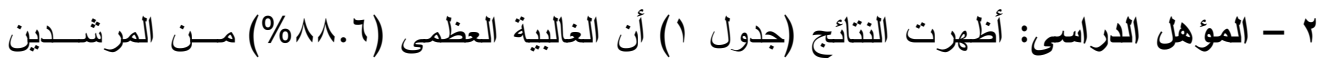

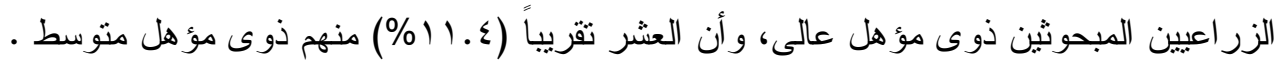

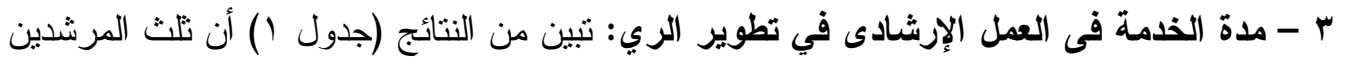

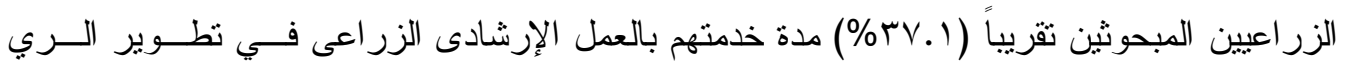




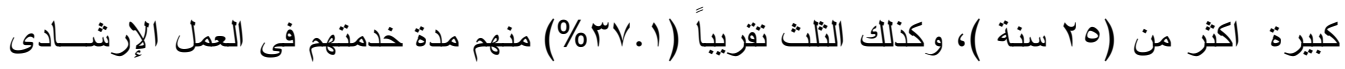

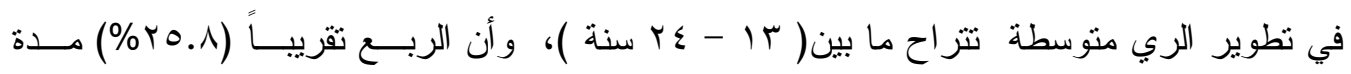

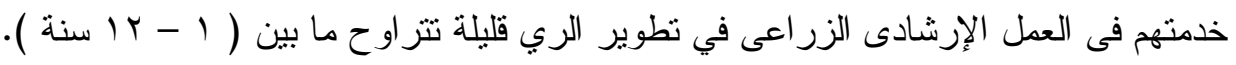

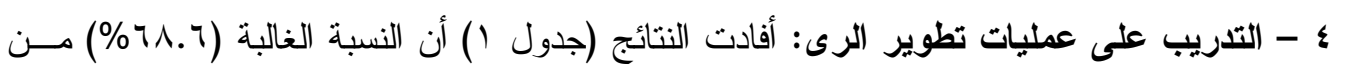

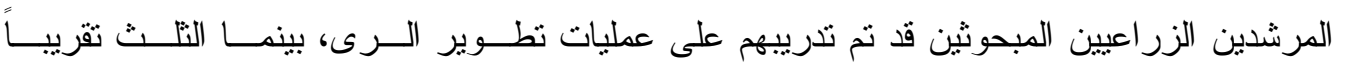

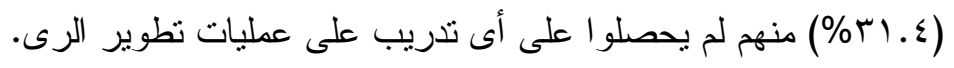

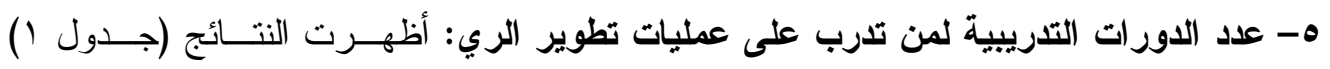

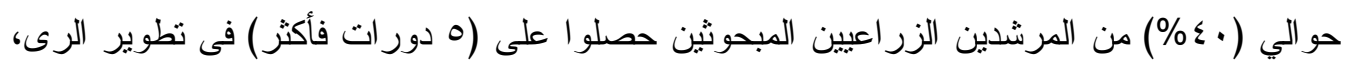

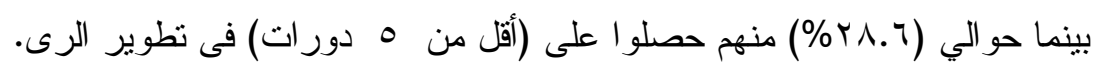
ب - مهندسى التوجيه المائى المبحوثين:

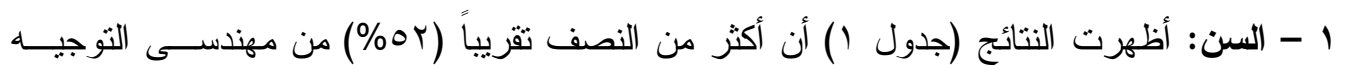

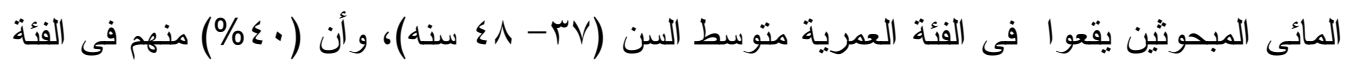

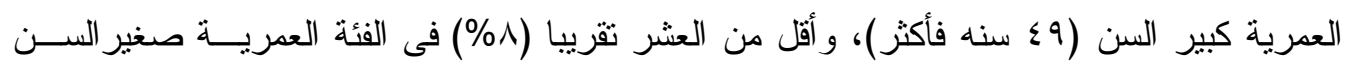

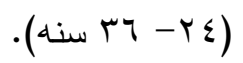
Y - المؤهل الدراسى: أوضحت النتائج (جدول ( ) أن غالبية مهندسى التوجيه المـائى المبحــوثين

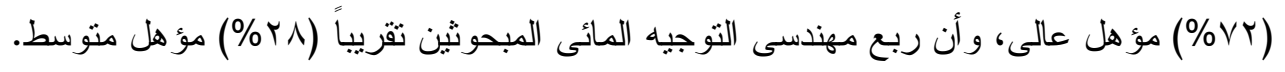

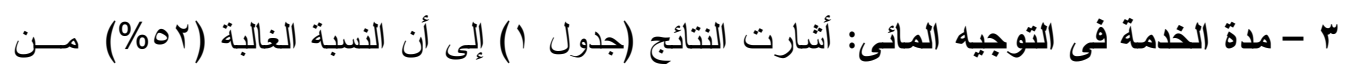

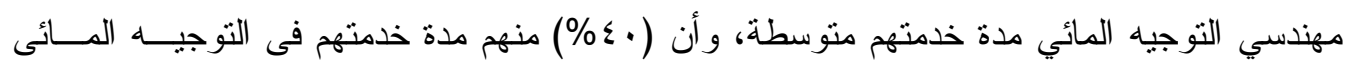

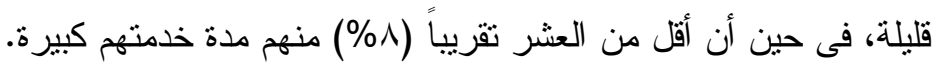

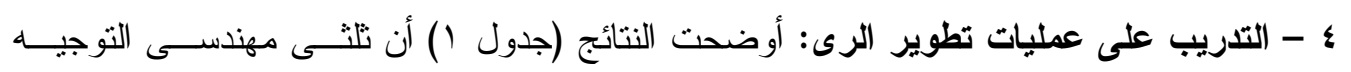

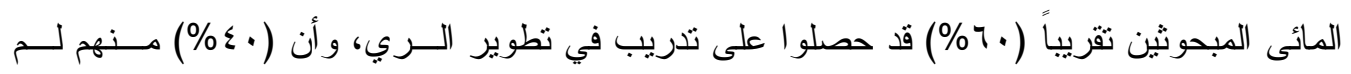
يحصلو ا على تدريب فى تطوير الرى.

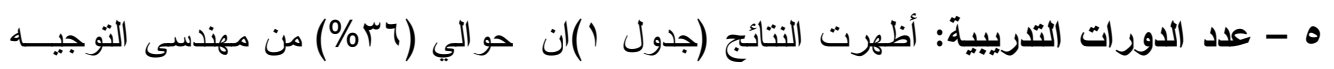

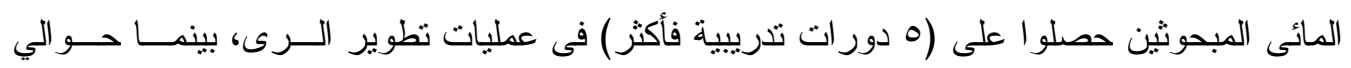

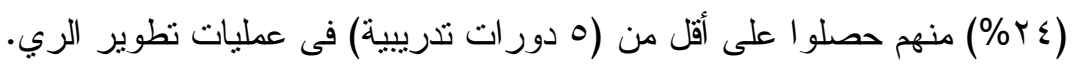


جدول رقم ( 1 ): توزيع المبحوثين وفقاً لمتغير اتهم الشخصية والمهنية

\begin{tabular}{|c|c|c|c|c|}
\hline \multicolumn{2}{|c|}{ مهنسي التوجيه المائى } & \multicolumn{2}{|c|}{ المرشدين الزراعيين } & \multirow[b]{2}{*}{ المتغيرات الشخصية والمهنية } \\
\hline$\%$ & العدد العد & $\%$ & 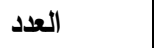 & \\
\hline \multicolumn{5}{|r|}{ 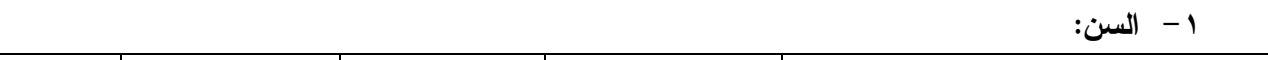 } \\
\hline$\wedge$ & r & $11 . \varepsilon$ & $\varepsilon$ & صغير السن (乏 r - بr) سنه \\
\hline or & 14 & r & ir & 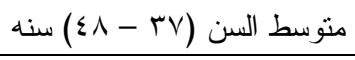 \\
\hline$\varepsilon \cdot$ & 1. & $0 \leqslant . r$ & 19 & كبير السن (9 ـ سنه فــأكثر) \\
\hline $1 \cdots$ & ro & $1 \cdots$ & ro & 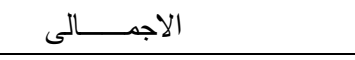 \\
\hline \multicolumn{5}{|r|}{ r - المؤهل الدراسى: } \\
\hline r^ & 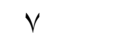 & $11 . \varepsilon$ & $\varepsilon$ & متوسط \\
\hline Vr & 11 & $\wedge \wedge .7$ & r & 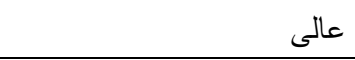 \\
\hline- & - & - & - & فوق العالى \\
\hline $1 \cdots$ & ro & $1 \cdots$ & ro & 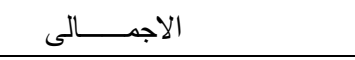 \\
\hline \multicolumn{5}{|c|}{ r- مدة الخدمة في عمليات تطوير الري: } \\
\hline$\varepsilon$. & 1. & Yo.^ & 9 & قليلة (1 - r I) سنه \\
\hline or & ir & rv.l & ir & متوسطه ( IT - I سنة) \\
\hline$\wedge$ & r & rv.l & ir & كبيرة (0 سنه فأكثر) \\
\hline $1 \cdots$ & ro & $1 \cdots$ & ro & 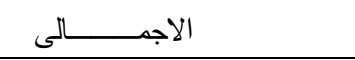 \\
\hline \multicolumn{5}{|c|}{ ـ - التدريب على عمليات تظوير الرى: } \\
\hline 7. & 10 & $7 \wedge .7$ & $r \varepsilon$ & 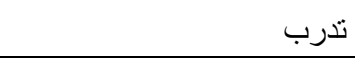 \\
\hline$\varepsilon$ & 1. & M. & 11 & لم يتدرب \\
\hline $1 \cdots$ & ro & $1 \cdots$ & ro & 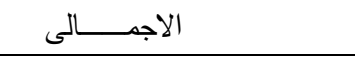 \\
\hline \multicolumn{5}{|c|}{ ه - عد الدورات التدريية التى حصلوا عليها في تظوير الري: } \\
\hline$r \leq$ & 7 & rA.7 & $1 \cdot$ & أقل من 0 دور ات \\
\hline r & 9 & $\varepsilon \cdot \cdots$ & $1 \varepsilon$ & 0 دور دات فأكثر \\
\hline$\varepsilon$ & $1 \cdot$ & M.乏 & 11 & 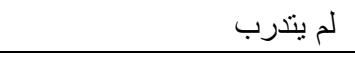 \\
\hline $1 \cdots$ & ro & $1 \cdots$ & ro & 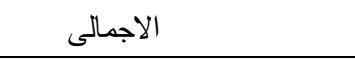 \\
\hline
\end{tabular}

المصدر : استمارة الاستبيان

\section{النتائج ومناقتشتها}

أولا: أهم المهام التي يجب أن يختص بها الارشاد الزراعي والتوجيه المائي وبــاقى المشــاركين

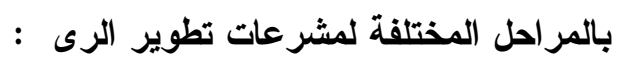
1 - أهم المهام التي يجب أن تختص بها الجهات المختلفة بمر احل مشروعات نطوير الري كما

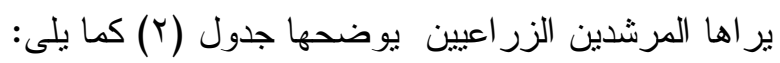

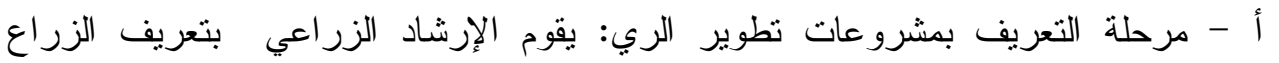

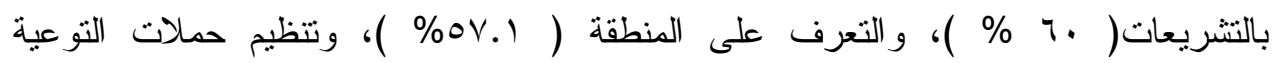




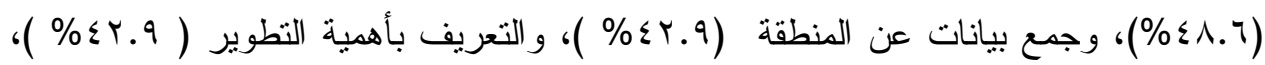

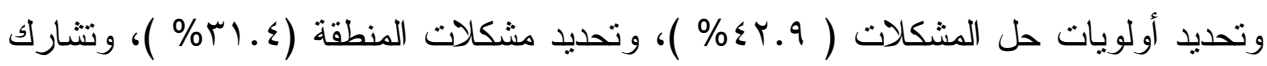

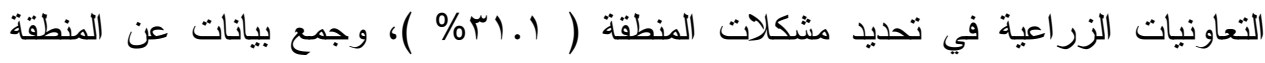

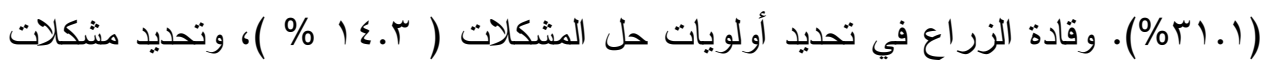

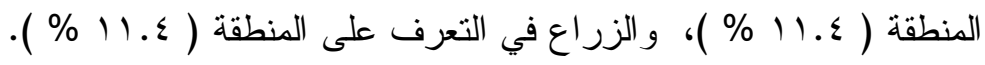

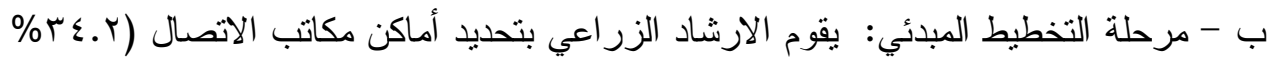

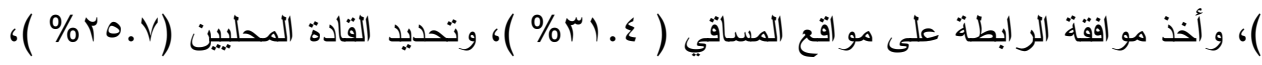

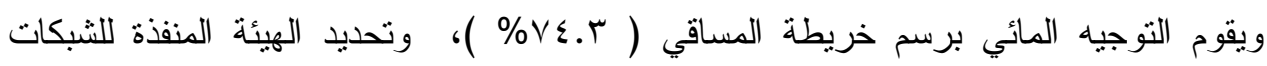

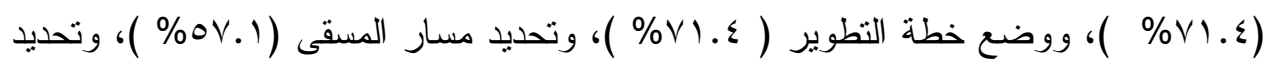

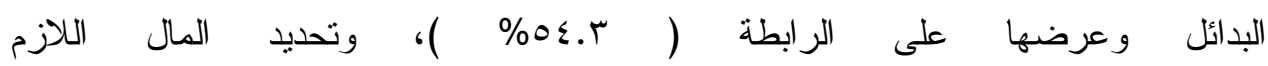

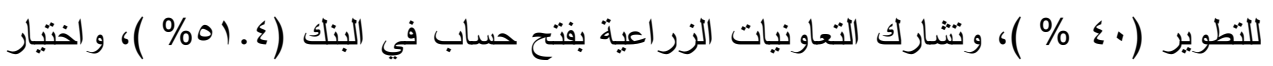

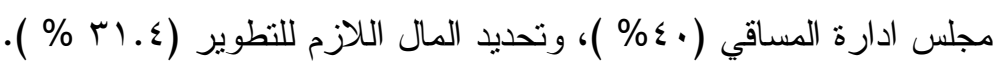

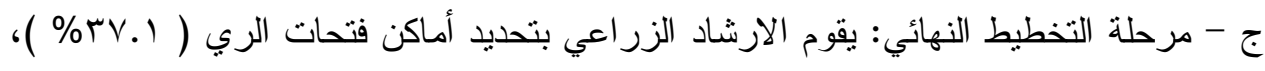

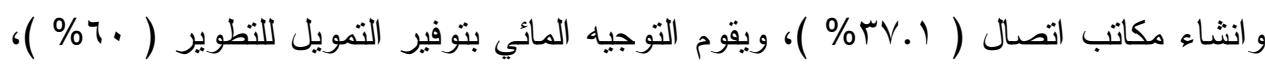

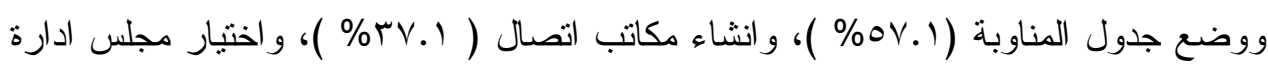

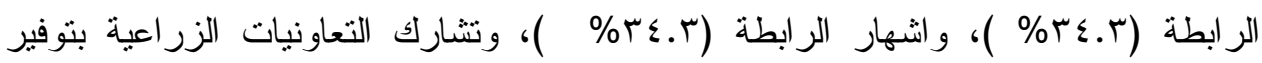

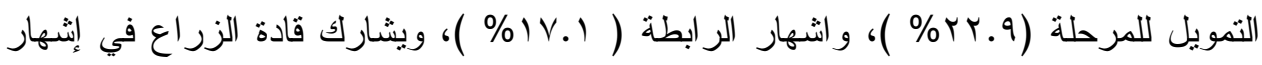

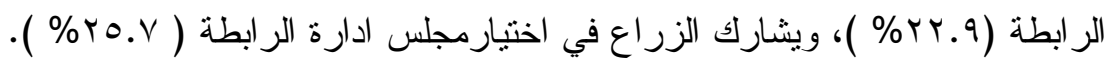

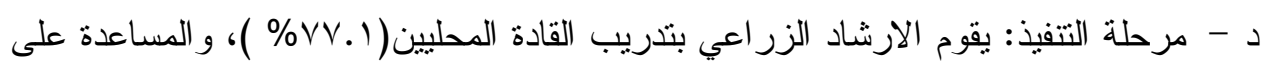

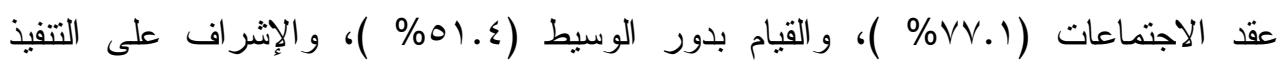

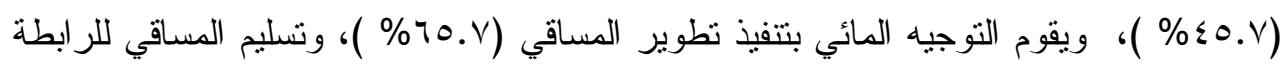

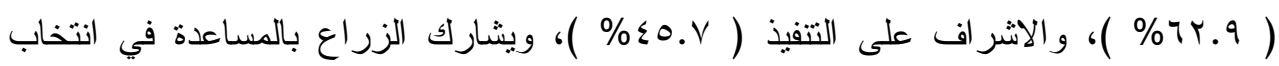

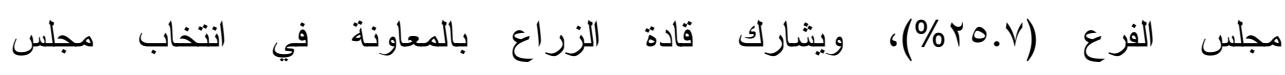

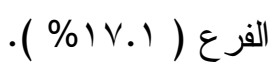

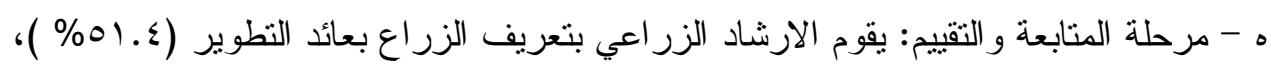

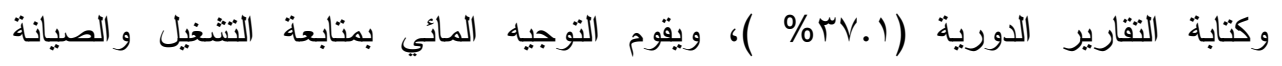

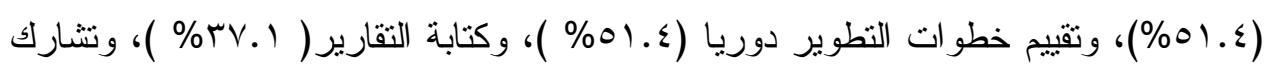

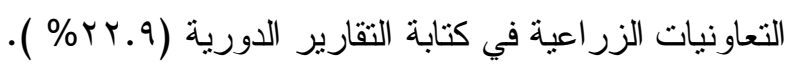


جدول رقم ( r ) ): المهام المتعلقة بمر احل مشروعات تطوير الرى و الجهات المختصة من وجة نظر المرشدين الزر اعبين المبحوثين

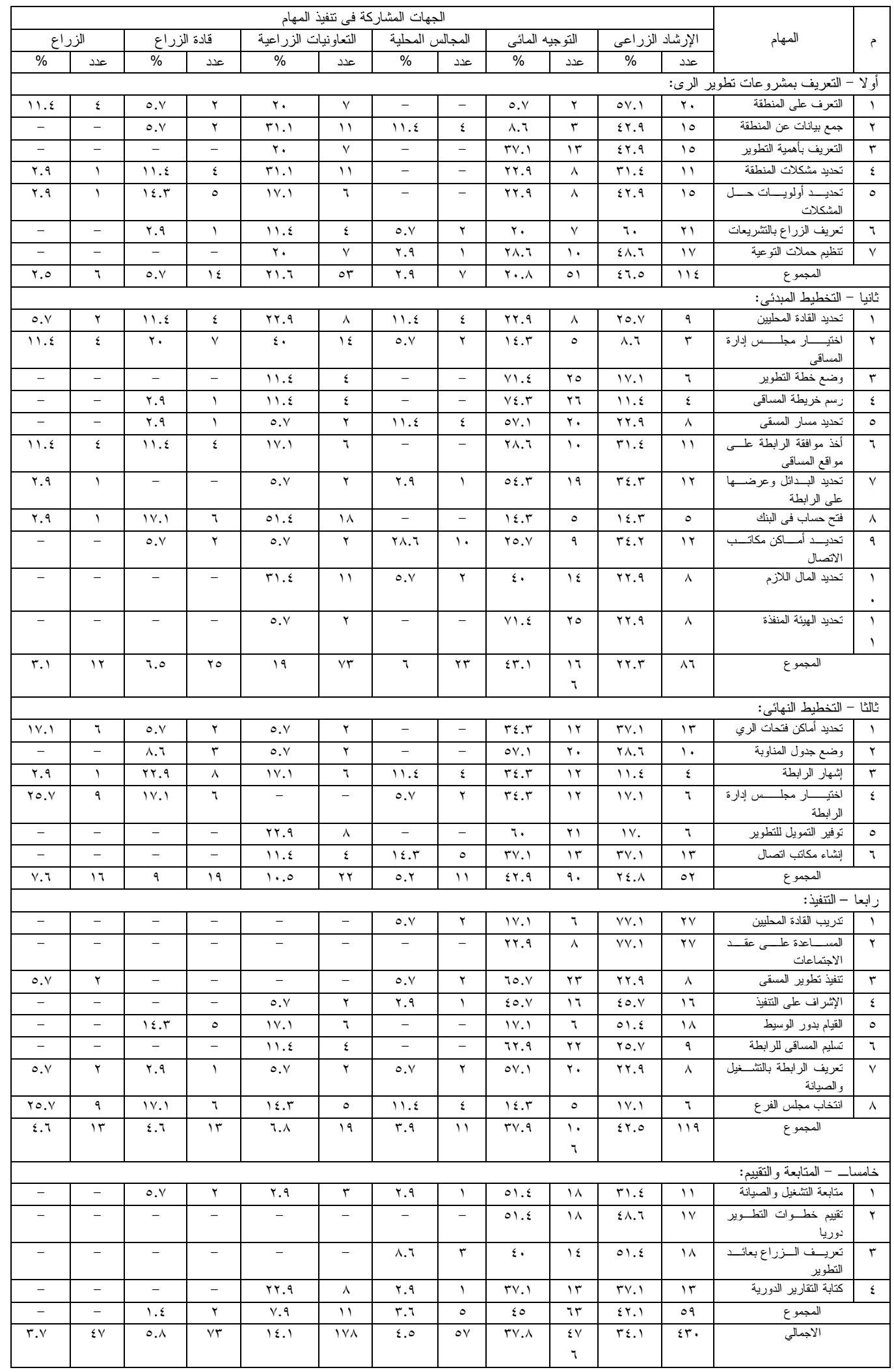


r- أهم المهام التي يجب أن تختص بها الجهات المختلفة بمراحل مشروعات تطوير الري من

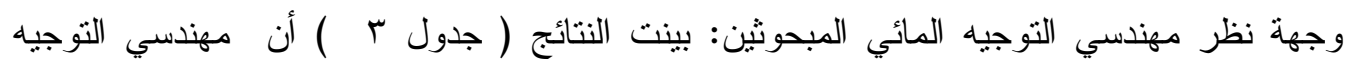
المائي المبحوثثن أفادوا أن مهام الجهات المختلفة المشاركة في مر احل مشروعات تطوير الري كانت

أ- مرحلة التعريف بمشروعات تطوير الري: يقوم الإرشاد الزراعي بتحديد أولويات حل

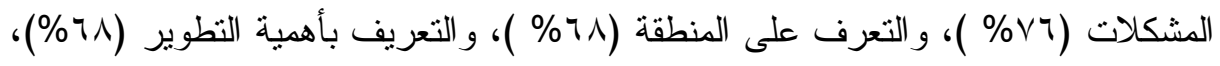

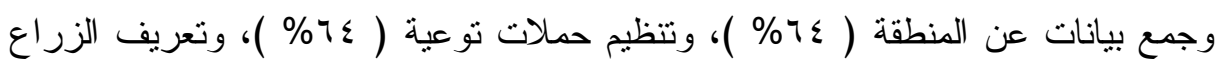

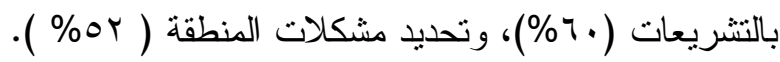

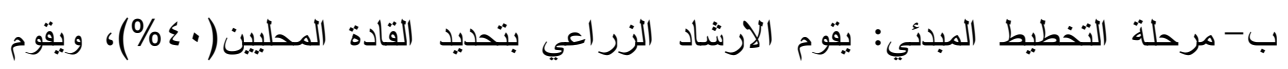

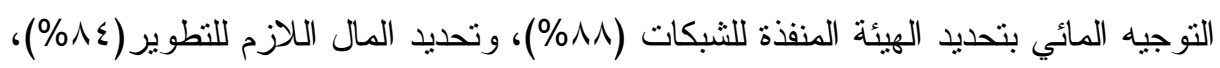

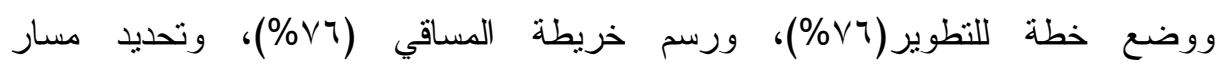

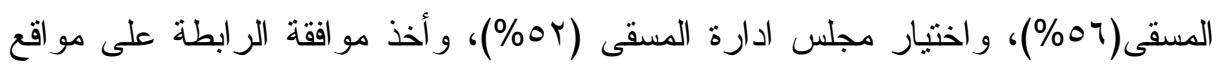

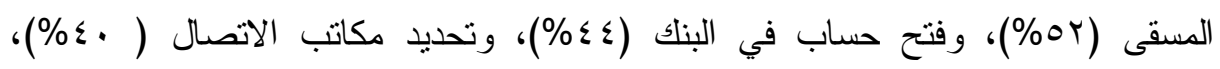

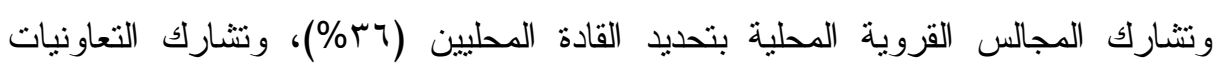
الزر اعية بفتح حساب في البنك (ع ب\%).

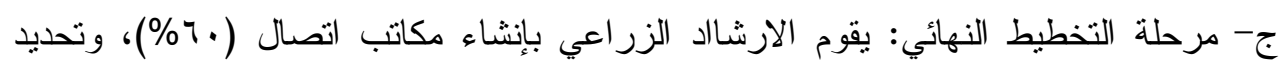

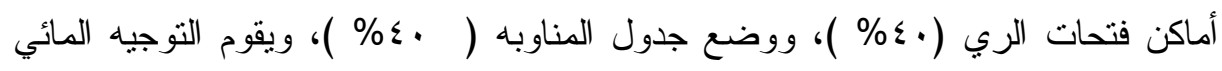
بتوفير التمويل للنطوير (ro\%) وبإنشار الر ابطة (

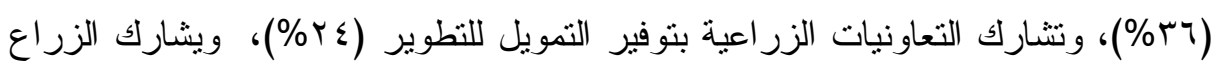

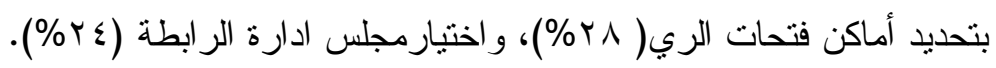

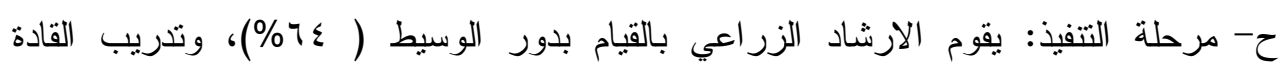

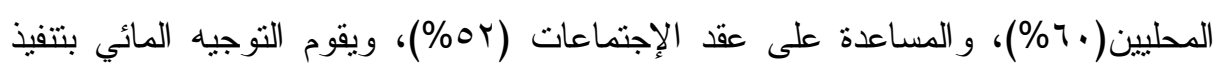

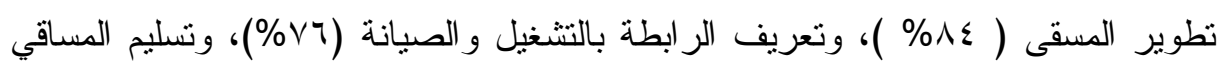

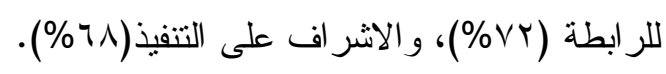

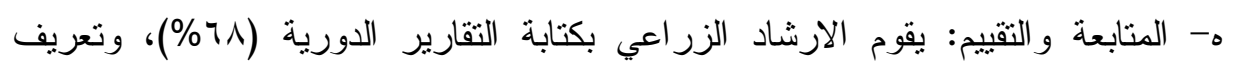

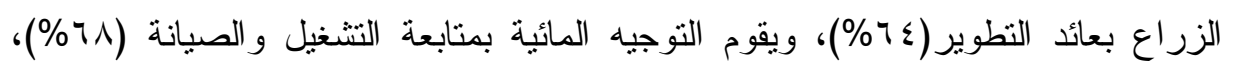

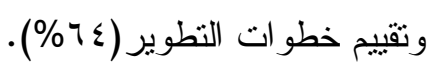


جدول رقم ( r ) ): المهام المتعقة بمر احل مشروعات تطوير الرى والجهات

المختصة من وجهة نظر مهندسي التوجيه المائي المبحوثين

\begin{tabular}{|c|c|c|c|c|c|c|c|c|c|c|c|c|c|}
\hline \multicolumn{12}{|c|}{ الجهات المشاركة فى تنفيذ المهام } & \multirow{3}{*}{ 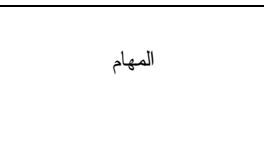 } & \multirow{3}{*}{ ? } \\
\hline \multicolumn{2}{|c|}{ الزراع } & \multicolumn{2}{|c|}{ 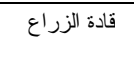 } & \multicolumn{2}{|c|}{ الز الزعاونيات } & \multicolumn{2}{|c|}{ المجالس المحلية } & \multicolumn{2}{|c|}{ التوجيه المائى } & \multicolumn{2}{|c|}{ الإرشاد الزراعى } & & \\
\hline$\%$ & عدد & $\%$ & عدد & $\%$ & عدد & $\%$ & عدد ع ل & $\%$ & عدد & $\%$ & عدد & & \\
\hline & & & & & & & & & & & & \multicolumn{2}{|c|}{ أولا- التعريف بمشروعات تطوير الرى: } \\
\hline- & - & $\xi$ & 1 & $\wedge$ & $r$ & $\xi$ & 1 & 17 & $\xi$ & १^ & IV & التعرف على المنطقة & 1 \\
\hline- & - & $\varepsilon$ & 1 & 17 & $\varepsilon$ & $\varepsilon$ & 1 & ir & $r$ & $7 \varepsilon$ & 17 & جمع بيانات عن المنطقة & $r$ \\
\hline- & - & - & - & $\varepsilon$ & 1 & - & - & ru & $\mathrm{v}$ & $7 \Lambda$ & iv & التعريف بأهمية التطوير & $r$ \\
\hline- & - & 17 & $\varepsilon$ & $\Lambda$ & $r$ & $\varepsilon$ & 1 & $r \cdot$ & 。 & or & ir & تحديد مشكلات المنطقة & $\varepsilon$ \\
\hline- & - & $\Lambda$ & $r$ & - & - & $\varepsilon$ & 1 & ir & $r$ & $\mathrm{VT}_{4}$ & 19 & تحديد أولويات حل الشككلات & 0 \\
\hline- & - & - & - & Ir & $r$ & $\lambda$ & $r$ & r. & o & \%. & 10 & تعريف الزراع بالتشريعات & 7 \\
\hline- & - & $\wedge$ & $r$ & - & - & $\varepsilon$ & 1 & $r \leq$ & 7 & $7 \leqslant$ & 17 & تنظيم حملات التوعية & $\mathrm{v}$ \\
\hline- & - & $0 . \mathrm{V}$ & 1. & 7.9 & ir & $\varepsilon$ & v & 11.9 & rT & $7 \varepsilon .7$ & $11 \%$ & \multicolumn{2}{|l|}{ المجموع } \\
\hline \multicolumn{14}{|c|}{ ثانيا - التخطيط المبدئى: } \\
\hline$\varepsilon$ & 1 & - & - & $\wedge$ & r & $r 4$ & 9 & ir & $r$ & «. & 1. & تحديد القادة المحليين & 1 \\
\hline$\varepsilon$ & 1 & $\xi$ & 1 & - & - & - & - & or & 14 & $\xi$ & 1. & اختيار مجلس إدارة المساقى & $r$ \\
\hline- & - & $\xi$ & 1 & - & - & - & - & $\mathrm{y}_{4}$ & 19 & $r$. & o & وضع خطة التطوير & $r$ \\
\hline- & - & - & - & - & - & - & - & $\mathrm{v}_{4}$ & 19 & $T \varepsilon$ & 7 & زسم خريطة المساقى & $\varepsilon$ \\
\hline$\Lambda$ & $r^{r}$ & $\Lambda$ & $r$ & $\begin{array}{c}- \\
-\end{array}$ & - & $\mathrm{A}$ & $r$ & 04 & $1 \leqslant$ & $r$. & o & تحديد مسار المسقى & 0 \\
\hline$\wedge$ & $r$ & - & - & - & - & $\varepsilon$ & 1 & or & ir & ri & 9 & أخذاقى مو افقة الر ابطة على مواقع & 7 \\
\hline- & - & $\Lambda$ & $r$ & $\varepsilon$ & 1 & - & - & or & ir & ז4 & 9 & تحديد البدائل & $\mathrm{v}$ \\
\hline$\varepsilon$ & 1 & $\wedge$ & $r$ & $r \varepsilon$ & 7 & - & - & $\varepsilon \leqslant$ & 11 & $r$. & 0 & فتح حساب فى البنك & $\wedge$ \\
\hline$\varepsilon$ & 1 & ir & $r$ & $\varepsilon$ & 1 & A & $r$ & $\varepsilon$. & 1. & rr & $\Lambda$ & تحديد مكاتب الاتصال & 9 \\
\hline- & - & - & - & - & - & $\varepsilon$ & 1 & $\wedge \varepsilon$ & $r$ & ir & $r$ & تحديد المال اللازم & 1 \\
\hline- & - & - & - & - & - & - & - & $\wedge \wedge$ & rr & ir & $r$ & تحديد الهيئة المنفذة & 1 \\
\hline r.9 & $\wedge$ & $\varepsilon$ & 11 & $r .1$ & 1. & 0.0 & 10 & ov.o & 101 & r9.0 & $V r$ & \multicolumn{2}{|l|}{ المجموع } \\
\hline \multicolumn{14}{|c|}{ ثالثا - التخطيط النهائى: } \\
\hline$r \wedge$ & $\mathrm{v}$ & $\xi$ & 1 & - & - & - & - & rA & $\mathrm{v}$ & $\xi$. & 1. & تحديد أماكن الفتحات & 1 \\
\hline 17 & $\varepsilon$ & 17 & $\varepsilon$ & - & - & - & - & rA & v & $\xi$ & 1. & وضع جدول المناوبة & $r$ \\
\hline- & - & $\pi$ & $r$ & $\xi$ & 1 & $\varepsilon$ & 1 & $\varepsilon \wedge$ & $\overline{T H}$ & $\begin{array}{rr}r \\
\end{array}$ & $\Lambda$ & إنشهار الر ابطة & $r$ \\
\hline$r \varepsilon$ & 7 & ir & $r$ & - & - & - & - & 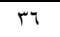 & 9 & rA & $\mathrm{v}$ & اختيار مجلس إدارة الرابطة & $\varepsilon$ \\
\hline- & - & - & - & $r \xi$ & 1 & - & - & or & ir & $r \leqslant$ & 7 & توفير التمويل للتطوير & 0 \\
\hline- & - & $\varepsilon$ & 1 & - & - & Ir & $r$ & $r \leqslant$ & 7 & 7. & 10 & إنثاء مكاتب اتصال & 7 \\
\hline $11 . r$ & IV & $\wedge$ & IT & ย.V & $v$ & r.V & $\varepsilon$ & $r 4$ & $0 \leqslant$ & $r v . r$ & 04 & \multicolumn{2}{|l|}{ المجموع } \\
\hline \multicolumn{14}{|c|}{ رابعا - التنفيذ: } \\
\hline- & - & - & - & - & - & $\wedge$ & $r$ & $r r$ & $\wedge$ & 7. & 10 & تندريب القادة المحليين & 1 \\
\hline- & - & 17 & $\varepsilon$ & - & - & Tr & $r$ & r. & . & or & ir & العساعدة على عقد الاجتماعات & $r$ \\
\hline- & - & - & - & - & - & $\varepsilon$ & 1 & $\Lambda \Sigma$ & $r$ & ir & $r$ & تيفيذ تطوير المسقى & $r$ \\
\hline- & - & - & - & - & - & - & - & $\pi$ & IV & $r \mu$ & $\wedge$ & الإثر اف على التنفيذ & $\varepsilon$ \\
\hline- & - & $\lambda$ & $r$ & - & - & - & - & $r \Lambda$ & v & $7 \varepsilon$ & 17 & القيام بدور الوسيط & 0 \\
\hline- & - & $\lambda$ & $r$ & - & - & - & - & VY & 11 & $r$. & 0 & تسلم المساقى للرابطة & 7 \\
\hline- & - & - & - & - & - & - & - & $\mathrm{Vy}$ & 19 & $T \leqslant$ & 7 & التعريف بالنشغيل & v \\
\hline 17 & $\varepsilon$ & 17 & $\xi$ & - & - & $\Lambda$ & $r$ & $r 4$ & 9 & $T \leq$ & 7 & انتخاب مجلس الفرع & $\wedge$ \\
\hline$r$ & $\varepsilon$ & 7 & IT & - & - & $\varepsilon$ & $\wedge$ & or & $1 . \varepsilon$ & r4 & VY & \multicolumn{2}{|l|}{ المجموع } \\
\hline & & & & & & & & & & & & 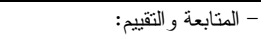 & \\
\hline- & - & $\Lambda$ & $r$ & - & - & - & - & $7 \lambda$ & iv & $r \varepsilon$ & 7 & متابعة التثنغيل & 1 \\
\hline- & - & - & - & - & - & - & - & $T \leqslant$ & 17 & mi & 9 & تقتيبم خطو ات التطوير & $r$ \\
\hline- & - & - & - & - & - & - & - & $r 4$ & 9 & $7 \varepsilon$ & 17 & تعريف الزراع بالعائد & $r$ \\
\hline- & - & - & - & - & - & - & - & rr & 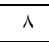 & 71 & iv & كتابة التقارير الدورية & $\varepsilon$ \\
\hline- & - & $r$ & $r$ & - & - & - & - & 0. & 0. & $\varepsilon \wedge$ & «^ & المجموع & \\
\hline r.r & $r q$ & $0 . Y$ & $\xi v$ & $r . r$ & $r q$ & $r . \Lambda$ & $r \varepsilon$ & $\varepsilon \leqslant . T$ & rq9 & $\varepsilon \cdot r$ & TIY & الاجمالي & \\
\hline
\end{tabular}


ثانيا: إمكاتية قيام العلاقة التكاملية بين الإرشاد الزراعي والتوجيه المائي في مجال مشروعات

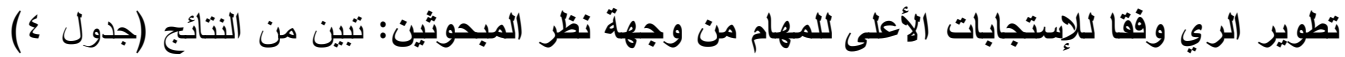

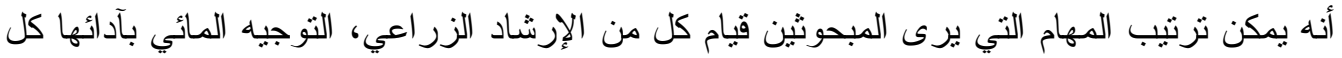

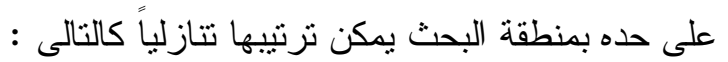
أ- يرى (ع \% \% ) من المبحوثين أن الارشاد الزراعى يجب ان يختص بالقيام بمرحلة التعريف

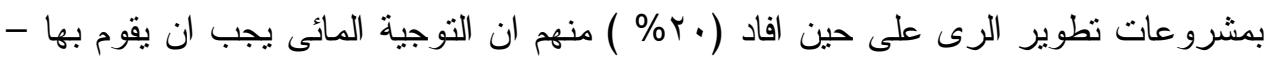

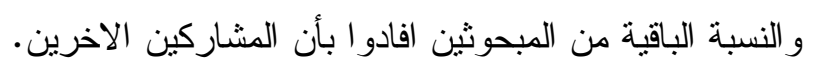

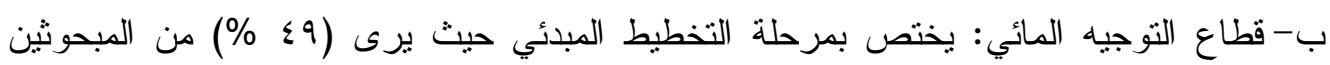

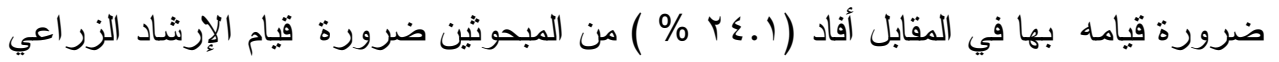

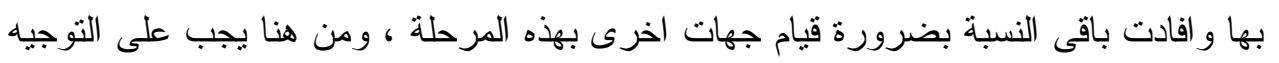

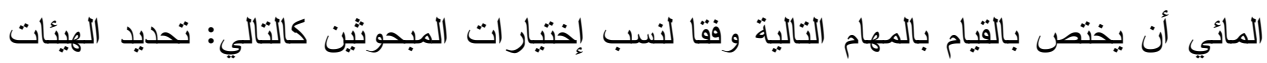

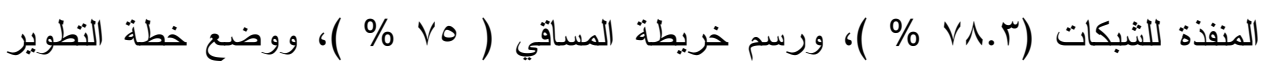

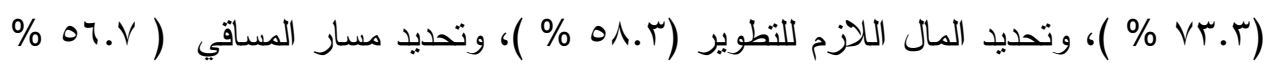

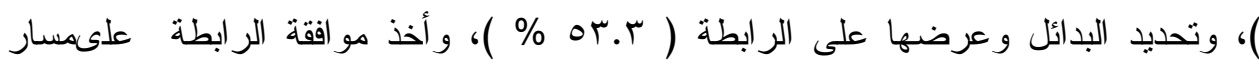

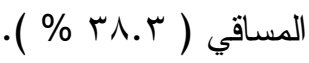

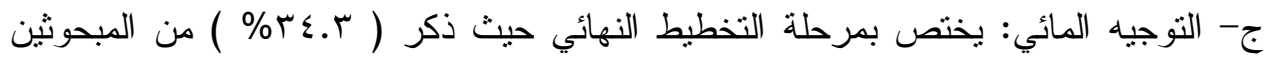

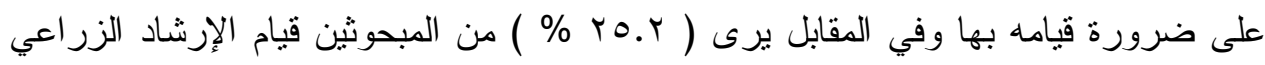

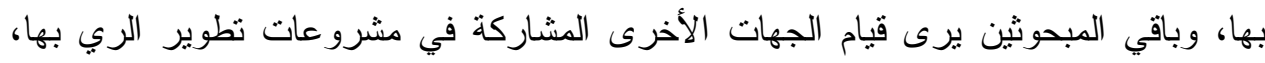

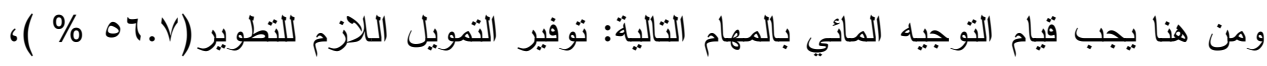

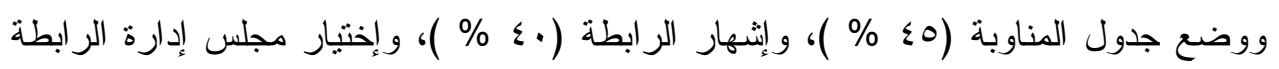

. (\% ro)

د- التوجيه المائي: يختص بمرحلة التتفيذ حيث يرى ( ^.ب؟ \% م ) من المبحوثين ضرورة

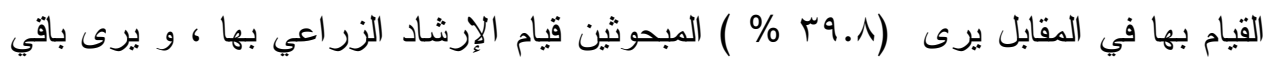

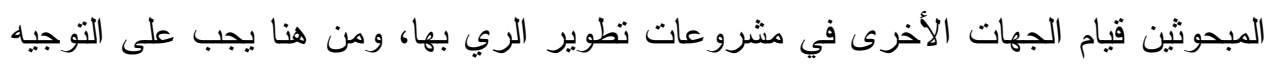
المائي

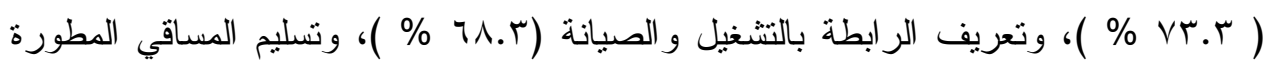

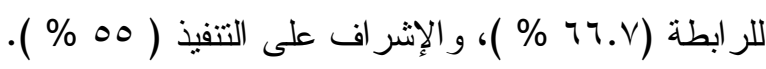

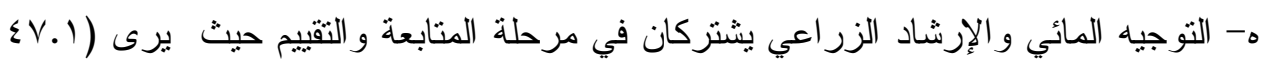

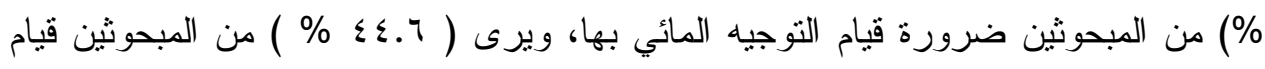

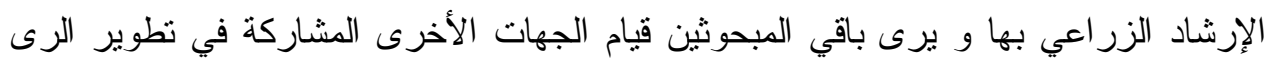

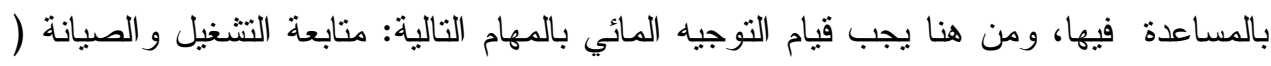

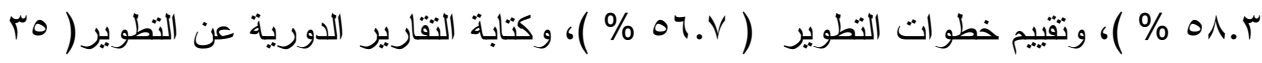

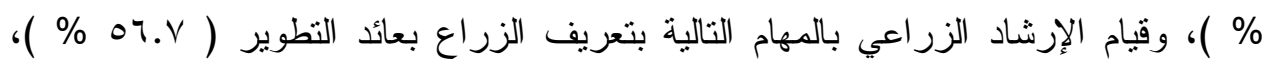

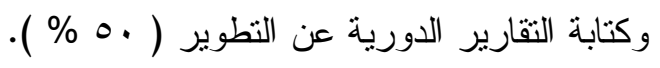


جدول رقم ( ) ): إمكانية التكامل بين الارشاد الزر اعي و التوجيه المائي وفقا للإستجابات

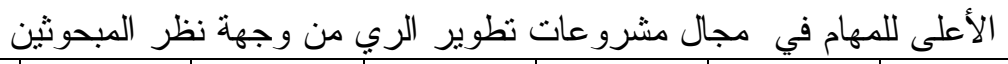

\begin{tabular}{|c|c|c|c|c|c|c|c|c|c|c|c|c|c|}
\hline \multicolumn{2}{|c|}{ الزراع } & \multicolumn{2}{|c|}{ 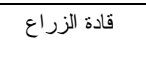 } & \multicolumn{2}{|c|}{ الزراعية } & \multicolumn{2}{|c|}{ مجالس المحليات } & \multicolumn{2}{|c|}{ النوجيه المائي } & \multicolumn{2}{|c|}{ الإرشاد الزر اعي } & \multirow[t]{2}{*}{ المهام } & \multirow[t]{2}{*}{ e } \\
\hline$\%$ & عدد & $\%$ & عدد & $\%$ & عدد & $\%$ & عدد & $\%$ & عدد & $\%$ & عدد & & \\
\hline \multicolumn{14}{|c|}{ أو لا: مرحلة التعريف بمشروعات تطوير الري: } \\
\hline 7.Y & $\varepsilon$ & 。 & r & 1.0 & 9 & $1 . \mathrm{V}$ & 1 & 1. & 7 & $11 . \mathrm{V}$ & rv & التعرف على الهنطقة & 1 \\
\hline- & - & 0 & $r$ & ro & 10 & A.r & 。 & 1. & 7 & $01 . \mathrm{Y}$ & $r$ & جمع البيانات عن المنطقة & $r$ \\
\hline- & - & - & - & Ir.r & ^ & - & - & rT.r & r. & or.r & rT & التعريف بأهمية التطوير & r \\
\hline $1 . \mathrm{V}$ & 1 & ir.r & $\Lambda$ & rI.r & ir & $1 . V$ & 1 & YI.V & ir & $\varepsilon$. & $r \varepsilon$ & تحديد مشكلات المنطقة & $\varepsilon$ \\
\hline $1 . \mathrm{V}$ & 1 & $11 . \mathrm{V}$ & $\mathrm{v}$ & 1. & 7 & $1 . \mathrm{V}$ & 1 & $1 A . r$ & 11 & $04 . \mathrm{V}$ & $r \varepsilon$ & تحديد أولويات حل المشكلات & 。 \\
\hline- & - & $1 . \mathrm{V}$ & 1 & $11 . \mathrm{r}$ & $\mathrm{v}$ & $T . V$ & $\varepsilon$ & $r$. & ir & T. & ri & تتعريسف الزراع بالتثريعات & 7 \\
\hline- & - & r.r & $r$ & $11 . v$ & $\mathrm{v}$ & $r . r$ & $r$ & Vั. & 17 & 00 & $r r$ & تنظيم حملات التو عبة & $\mathrm{v}$ \\
\hline 1. & 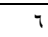 & $0 . V$ & rई & 10.0 & 70 & $r . r$ & $1 \leqslant$ & r. & $\Lambda \varepsilon$ & $0 \leqslant$ & TrY & \multicolumn{2}{|c|}{ 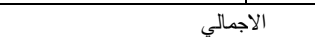 } \\
\hline
\end{tabular}

\begin{tabular}{|c|c|c|c|c|c|c|c|c|c|c|c|c|c|}
\hline \multicolumn{14}{|c|}{ ثانيا: مرحلة التخطيط المبدئي: } \\
\hline 。 & $r$ & T.V & $\varepsilon$ & 17.8 & 1. & YI.V & ir & $1 \mathrm{i} . \mathrm{T}$ & 11 & r.v & 19 & تحديد القادة المحليين & 1 \\
\hline A.r & o & $1+r . r$ & $\wedge$ & rT.r & $1 \varepsilon$ & r.r & r & $r$. & is & rI.V & ir & اختبار مجلس ادارة المساقي & r \\
\hline- & - & $1 . \mathrm{V}$ & 1 & 7.8 & $\varepsilon$ & - & - & Vr.r & $\leqslant \leqslant$ & iN.r & 11 & وضع خطة التطوير & $r$ \\
\hline- & - & $1 . \mathrm{V}$ & 1 & 7. .2 & $\varepsilon$ & - & - & vo & 织 & $17 . \mathrm{V}$ & 1. & رسم خريطة المساقي & $\varepsilon$ \\
\hline r.r & r & 。 & r & r.r & r & 1. & 1 & $07 . \mathrm{V}$ & $r \varepsilon$ & r..v & ir & تحديد مسار المساقي & 。 \\
\hline 1. & 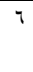 & 7.9 & $\xi$ & 1. & 7 & $1 . \mathrm{V}$ & 1 & rA.T & rr & rT.r & $r$. & أخذ مو افقة الرابطة على & 1 \\
\hline $1 . \mathrm{V}$ & 1 & r.r & r & o & $r$ & $1 . \mathrm{V}$ & 1 & or.r & rr & ro & $r$ & تحديد البدائل وعرضها على & $\mathrm{v}$ \\
\hline r.r & $r$ & $1 \% . r$ & $\wedge$ & $\varepsilon$. & $T \varepsilon$ & - & - & r..Y & 17 & $17 . \mathrm{V}$ & 1. & فتح حساب في البنك & $\wedge$ \\
\hline $1 . V$ & 1 & $7 . \%$ & $\varepsilon$ & $\circ$ & $r$ & $r$. & ir & $r . v$ & 19 & rT.r & $r$. & تحديد مكاتب الاتصال & 9 \\
\hline- & - & - & - & $11 . r$ & 11 & - & $r$ & $01 . r$ & ro & $11 . r$ & 11 & تحديد المال اللازم للتطوير & 1. \\
\hline- & - & - & - & r.r & $r$ & - & - & VA.r & $\varepsilon v$ & 1 in.r & 11 & تحديد الهيئة المنفذة & 11 \\
\hline$r .$. & $r$. & 0.1 & $r 4$ & $1 Y .7$ & Nr & 0.1 & rA & $\leq 9$ & TrE & $r \leqslant .1$ & 109 & & الإجه \\
\hline
\end{tabular}

\begin{tabular}{|c|c|c|c|c|c|c|c|c|c|c|c|c|c|}
\hline \multicolumn{14}{|c|}{ ثالثا: مرحلة التخطيط النهائي: } \\
\hline YI.V & ir & - & $r$ & $r . r$ & r & - & - & $\mu . \mathrm{r}$ & 19 & $r \Lambda . r$ & $r$ & تحديد أماكن فتحات الري & 1 \\
\hline T.V & $\varepsilon$ & $11 . \mathrm{V}$ & $\mathrm{r}$ & r.r & r & - & - & $\sum_{0}$ & Tr & rr.r & $r$. & وضع جدول المناوبة & r \\
\hline $1 . \mathrm{V}$ & 1 & $1 \Lambda . r$ & 11 & 11.1 & $\mathrm{r}$ & A.r & 。 & 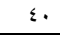 & $r \varepsilon$ & $r$. & ir & إثشهار الرابطة & $r$ \\
\hline ro & 10 & 10 & 9 & - & - & r.r & r & ro & r) & ri.v & ir & إختتار مجلس إدارة الرابطة & $\varepsilon$ \\
\hline- & 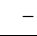 & - & - & rT.r & $1 \varepsilon$ & - & - & $07 . \mathrm{V}$ & $r \varepsilon$ & r. & ir & توفير التمويل اللازم للتطوير & . \\
\hline- & - & $1 . \mathrm{v}$ & 1 & 7.1 & $\varepsilon$ & $1 r . r$ & $\wedge$ & r..v & 19 & 纟.. & rA & إنثاء مكاتب الإتصال & 1 \\
\hline 9.1 & $r$ & 0.7 & $r$ & N.1 & rq & 纟.Y & 10 & $r \varepsilon . r$ & $1 \leqslant \leqslant$ & TO.Y & 1.7 & & \\
\hline
\end{tabular}

\begin{tabular}{|c|c|c|c|c|c|c|c|c|c|c|c|c|c|}
\hline \multicolumn{14}{|c|}{ رابعا: مرحلة التنفيذ: } \\
\hline- & - & - & - & - & - & T.V & $\varepsilon$ & rr.r & $1 \varepsilon$ & v. & $\varepsilon r$ & تدريب القادة المحليين & 1 \\
\hline- & - & 7.V & $\varepsilon$ & - & - & 。 & $r$ & r..V & it & 74. & $\varepsilon$. & الاجتماعات على عقد & r \\
\hline r.r & r & - & - & - & - & 。 & $r$ & Vr.r & 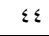 & $11 . r$ & 11 & تنفيذ تطوير المسقى & $r$ \\
\hline- & - & - & - & r.T & r & $1 . \mathrm{V}$ & 1 & 00. & $r$ & $\leqslant$. & $r \varepsilon$ & الاثشر اف على التنفيذ & $\varepsilon$ \\
\hline- & - & $11 . \mathrm{V}$ & $\mathrm{v}$ & 1. & 1 & - & - & r..v & ir & $07 . \mathrm{V}$ & $r \varepsilon$ & القيام بدور الوسيط & 。 \\
\hline- & - & r.r & r & 7.V & $\varepsilon$ & - & & $77 . \mathrm{V}$ & $\varepsilon$. & $r+r$ & $1 \varepsilon$ & تسليم المساقي للر ابطة & 1 \\
\hline r.r & r & I.V & 1 & r.T & r & r.r & r & Tu.r & « & $r+r$ & $1 \leqslant$ & ت تعريف الر ابطة بالتشغيل & $\mathrm{v}$ \\
\hline r..v & 15 & $17 . \mathrm{V}$ & 1. & A.r & 。 & 1. & 1 & rr.r & $1 \leqslant$ & r. & ir & انتخاب مجلس الفرع & $\wedge$ \\
\hline T.1 & 10 & $0 . r$ & ro & $r .9$ & 19 & $r .9$ & 19 & $\varepsilon r . \Lambda$ & $r$ r. & $r 9.1$ & 191 & & \\
\hline
\end{tabular}

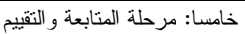

\begin{tabular}{|c|c|c|c|c|c|c|c|c|c|c|c|c|c|}
\hline- & - & T.V & $\varepsilon$ & o & $r$ & $1 . v$ & 1 & $0 \wedge . r$ & ro & rA.r & IV & متابعة النتشغيل و الصيانة & 1 \\
\hline- & - & - & - & - & - & - & - & $07 . \mathrm{Y}$ & $r \varepsilon$ & $\varepsilon r . r$ & rY & تقييم خطو ات التطوير دوريا & r \\
\hline- & - & - & - & - & - & $\circ$ & $r$ & rA.r & rr & $07 . \mathrm{V}$ & $r \varepsilon$ & تعريف الزر اع بعائد النطوير & r \\
\hline- & & - & - & ir.r & A & $I . V$ & 1 & ro & ri & $0 \ldots$ & $r$. & كتابة الثقارير الدورية & $\varepsilon$ \\
\hline- & - & 1.7 & $\varepsilon$ & $\{.7$ & 11 & $r .1$ & $\circ$ & $\leqslant \vee .1$ & 114 & $\leqslant \leqslant .7$ & 1.1 & \multicolumn{2}{|c|}{ لالإجمالي } \\
\hline r.o & $\mathrm{VT}$ & 0.7 & ir. & 9.7 & $r \cdot v$ & $\varepsilon . Y$ & 91 & $\varepsilon \cdot .0$ & AVo & r... & VAY & \multicolumn{2}{|c|}{ الإجمالي العام } \\
\hline
\end{tabular}

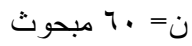

المصدر: مستخرج من جدولي (r، r ) من النتائج 
ويبين ( جدول 0 ) أنه أمكن توزيع المهام على الجهات المشاركة في مشروعات تطوير الري وفقا

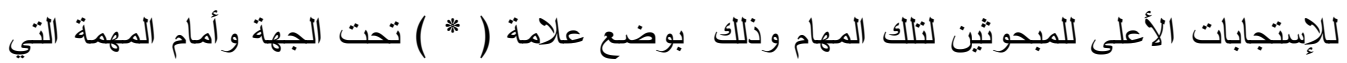
يمكن أن يشارك بها الإرشاد الزر اعي أو التوجيه المائي لإمكان قيام علاقة تكاملية فيما بينهما و وفقا

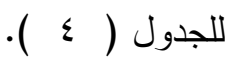

$$
\begin{aligned}
& \text { جدول رقم (0): نوزيع المهام على الجهات المشاركة في مشروعات } \\
& \text { تطوير الري وفقا للإستجابات الأعلى للمبحوثين }
\end{aligned}
$$

\begin{tabular}{|c|c|c|c|c|c|c|c|}
\hline \multicolumn{6}{|c|}{ الجهات المشاركة فى تتفيذ المهام } & \multirow{2}{*}{ 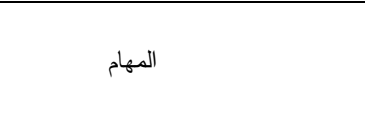 } & \multirow[b]{2}{*}{5} \\
\hline \multirow[t]{14}{*}{ الز الزراع } & الزراع & الزعاونية التية & المحلية المالس & التوجيه & الزر اعي & & \\
\hline & & & & & & \multicolumn{2}{|c|}{ أو لا: مرحلة التعريف بمشروعات تطوير الري: } \\
\hline & & & & & $*$ & التعرف على المنطقة & 1 \\
\hline & & * & & & * & جمع بيانات عن المنطقة & $r$ \\
\hline & & & & & * & التعريف بأهمية النطوير & $r$ \\
\hline & & * & & & * & تحديد مشاكل المنطقة & $\varepsilon$ \\
\hline & & & & & * & تحديد أولويات حل المشاكل & 。 \\
\hline & & & & & * & تعريف الزر اع بالتشريعات & 7 \\
\hline & & & & * & & تتظيم حملات التوعية & $\mathrm{V}$ \\
\hline & & & & & & \multicolumn{2}{|c|}{ ثانيا: مرحلة التخطيط المبئي: } \\
\hline & & * & * & & * & تحديد القادة المحليين & 1 \\
\hline & & * & & & & اختيار مجلس ادارة المسقى & r \\
\hline & & & & * & & وضع خطة النطوير & $r$ \\
\hline & & & & * & & رسم خريطة المساقي & $\varepsilon$ \\
\hline * & & & & * & & تحديد مسار المسقى & 0 \\
\hline & & & & * & & أخذ مو افقة الر ابطة على مو اقع المساقي & 7 \\
\hline & & & & * & & تحديد البدائل و عرضها على الر ابطة & $\mathrm{V}$ \\
\hline & & * & & * & & فتح حساب في البنك & $\wedge$ \\
\hline & & & * & & * & تحديد مكاتب الاتصال & 9 \\
\hline & & & & * & & تحديد المال اللازم للنطوير & $1 \cdot$ \\
\hline & & & & * & & تحديد الهيئة المنفذة للشبكات & 11 \\
\hline & & & & & & \multicolumn{2}{|c|}{ ثالثا: مرحلة التخطيط النهائي: } \\
\hline \multirow[t]{3}{*}{ * } & & & & & * & تحديد مكان فتحات الري & 1 \\
\hline & & & & * & & وضع جدول المناوبة & r \\
\hline & & & & * & & اشهار الر ابطة & $r$ \\
\hline \multirow[t]{11}{*}{$*$} & & & & * & & اختبار مجلس ادارة الر ابطة & $\varepsilon$ \\
\hline & & * & & * & & توفير التمويل للنطوير & $\circ$ \\
\hline & & & & & $*$ & انشاء مكاتب الاتصال & 7 \\
\hline & & & & & & \multicolumn{2}{|c|}{ رابعا: مرحلة التنفيذ: } \\
\hline & & & & & * & تذريب القادة المحليين & 1 \\
\hline & & & & & 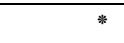 & المساعدة على عقد الاجتماعات & $r$ \\
\hline & & & & * & & تتفيذ تطوير الري & $r$ \\
\hline & & & & $*$ & & الاشر اف على التنفيذ & $\varepsilon$ \\
\hline & & & & & * & القيام بدور الوسبط & $\circ$ \\
\hline & & & & * & & نسليم المساقي للر ابطة & 7 \\
\hline & & & & * & & تعريف الر ابطة بالتشغيل و الصيانة & $\mathrm{v}$ \\
\hline \multirow[t]{6}{*}{ * } & * & & & & & انتخاب مجلس الفرع & $\wedge$ \\
\hline & & & & & & \multicolumn{2}{|c|}{ خامسا: مرحلة المتابعة و التقييم: } \\
\hline & & & & $*$ & & متابعة النشغيل و الصيانة & 1 \\
\hline & & & & $*$ & & تقييم خطو ات النطوير دوريا & r \\
\hline & & & & & * & تعريف الزر اع بعائد النطوير & $r$ \\
\hline & & * & & * & * & كتابة الثقارير الدورية & $\varepsilon$ \\
\hline
\end{tabular}

ن = • 7 مبحوث

المصدر : مستخلص من النتائج بجدول ( ع بل ) 
ثالثا: المشكلات التي تعوق قيام العلاقة التكاملية بين الإرشاد الزراعى، والتوجيه المائى وفقا لآراء

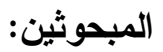

تبين من (جدول ؟) أن أهم المشكلات التى تعوق العلاقة التكاملية بين الارشاد الزر اعى، التوجيه المائى وفقا لتكر ار اختبار ات المبحوثين قد امكن ترتيب هذه المشكلات ترتيبا تتازليا وفقا

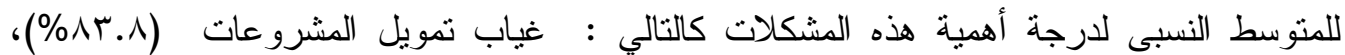

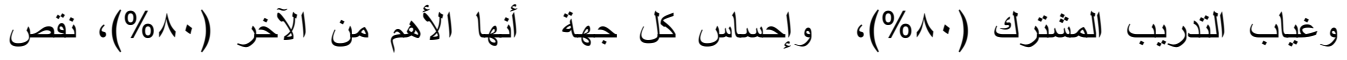

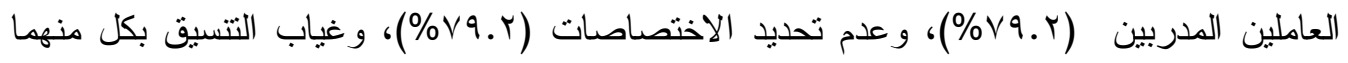

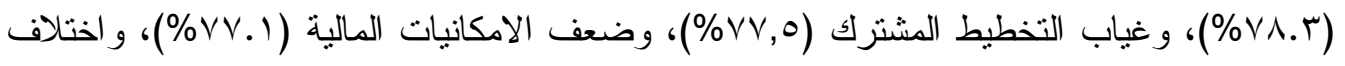

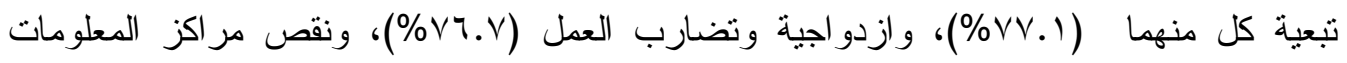

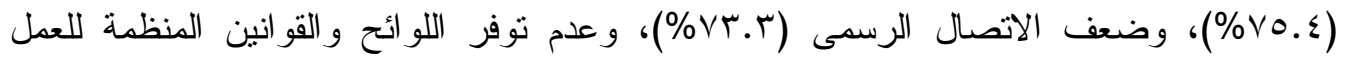

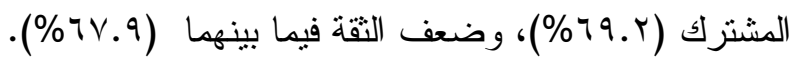
جدول رقم ( 1 ) ): المشكلات التي تعوق قيام العلاقة التكاملية بين قطاعي الإرشاد الزراعي، و التوجيه المائى وفقا لآراء المبحوثين

\begin{tabular}{|c|c|c|c|c|c|c|c|c|c|c|c|}
\hline \multirow{4}{*}{$\begin{array}{c}\text { النسبى } \\
\text { المتوسط } \\
\text { \% }\end{array}$} & \multirow{4}{*}{ الدنوسطة } & \multicolumn{8}{|c|}{ درجة تو اجد المشكلة } & \multirow{4}{*}{ المشكلات } & \multirow{4}{*}{ r } \\
\hline & & \multirow{2}{*}{\multicolumn{2}{|c|}{ الأهمية }} & \multirow{2}{*}{\multicolumn{2}{|c|}{ متوسطة }} & \multirow{2}{*}{\multicolumn{2}{|c|}{ منخفضة }} & \multirow{2}{*}{\multicolumn{2}{|c|}{ موجودة غير }} & & \\
\hline & & & & & & & & & & & \\
\hline & & $\%$ & عدد & $\%$ & عدد & $\%$ & عدد & $\%$ & عدد & & \\
\hline AT.A & r.乏 & $0 \lambda . r$ & ro & ro & 10 & 1. & 7 & $7 . \mathrm{V}$ & $\varepsilon$ & غباب تمويل المشروعات & 1 \\
\hline ᄉ. & r.r & $\leq \Upsilon . V$ & rA & ro & r & 1. & 7 & A.r & 。 & غياب التكريب المشترك & r \\
\hline$\wedge$. & r.r & r.r. & r & r..V & r & 17.8 & 1. & A.r & 。 & إحساس كل جهة انها الاهد & r \\
\hline Vq.r & r.r & 0. & $r$. & ro & 10 & $17 . \mathrm{V}$ & 1. & $\lambda . r$ & $\circ$ & نقص العاملين المدربين & $\varepsilon$ \\
\hline Vq. r & r.r & $\varepsilon \wedge . \Gamma$ & rq & r.. & 19 & A.r & 。 & $11 . \mathrm{V}$ & v & عدم تحديد الاختصاصات & 。 \\
\hline VA.r & r.) & $\leq 0$ & rV & rA.r & iv & rI.V & ir & 0 & $r$ & غياب التتسيق بكل منهما & 7 \\
\hline VV.o & r.1 & rA.r & r & rA.r & r & in.r & 11 & 0 & $r$ & غباب التخطيط الششترك & $v$ \\
\hline$V V_{.1}$ & r.l & «l.v & ro & M.V & 19 & r. & ir & $7 . \mathrm{V}$ & $\varepsilon$ & ضعف الإمكانيات المالية & $\wedge$ \\
\hline V.. I & r.) & $\varepsilon$. & $r \leqslant$ & ro & Y) & iᄉ.r & 11 & 7.V & $\varepsilon$ & اختّلاف تبعية كل جهية & 9 \\
\hline VI.V & r.) & $\varepsilon r . r$ & r & r..v & 19 & Ir.r & $\wedge$ & $11 . \mathrm{V}$ & v & ازدواجية وتضارب العصل & 1. \\
\hline Vo. & r & $\varepsilon$. & $r \varepsilon$ & $r$. & 11 & r..V & r & A.r & 。 & نقص مر اكز الععلومات & 11 \\
\hline vr.t & r.q & ro & r & ro & r) & $11 . r$ & 11 & $11 . \mathrm{V}$ & v & ضعف الاتصال الرسمى & ir \\
\hline 79.5 & r.A & r..v & 19 & $r \cdot$ & 11 & r..V & r & 17.8 & 1. & عدم توفر اللوائح و القوانين & ir \\
\hline & & & & & & & & & & المنظمة للعل المشترك ك & \\
\hline $7 V .9$ & r.V & r.r & $r$. & M.V & 19 & $\lambda . r$ & o & Y..V & 17 & ضعتف الثنة فيما بينهما & $1 \leqslant$ \\
\hline
\end{tabular}


ويتضح ان نقص كل من التمويل للعمل المشترك، و التدريب المشترك بينهما، و إحساس كل منهما أنه الأهم في نظوير الري، من أهم المشكلات التي تعوق قيام العلاقة التكاملية فيما بينهما والتغلب عليها سوف بساعد على توفير الوقت و الجهد و المال في ظل ندرة الموارد المائية ومحدودية رقعة الارض الزر اعية.

رابعا: وسائل تقوية العلاقة التكاملية بين الإرشاد الزراعى، و التوجيه المائى وفقا لآراء المبحوثين: اوضحت النتائج (جدول V) انه امكن نرنيب وسائل تقوية العلاقة التكاملية بين الإرشاد

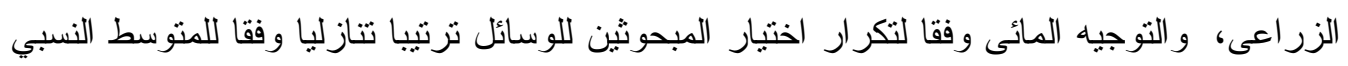

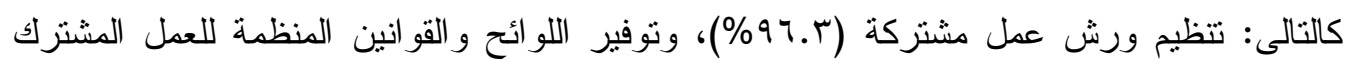

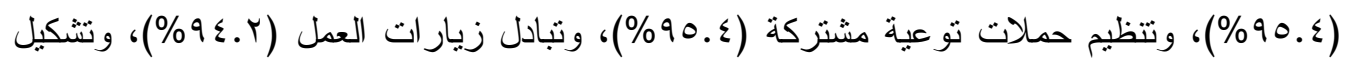

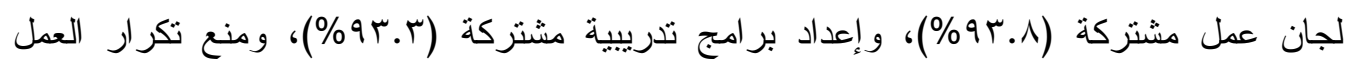

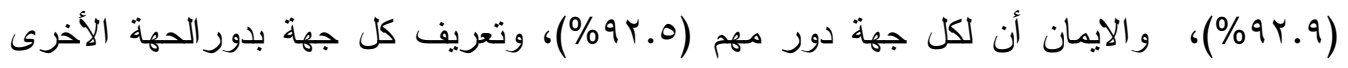

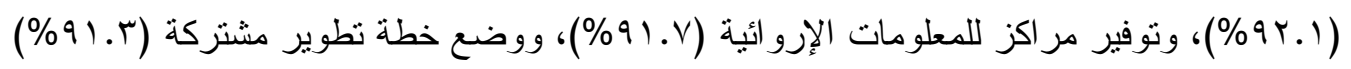

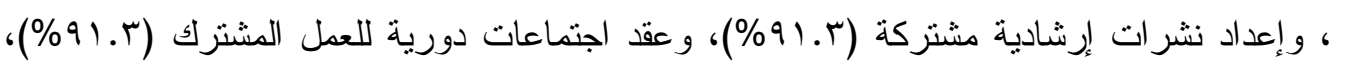

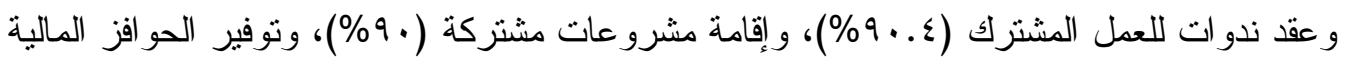

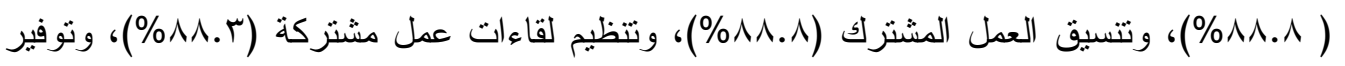

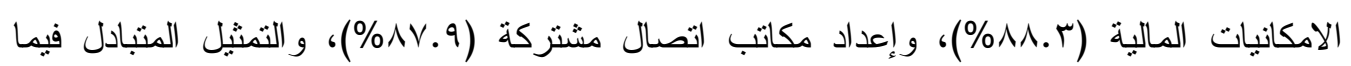

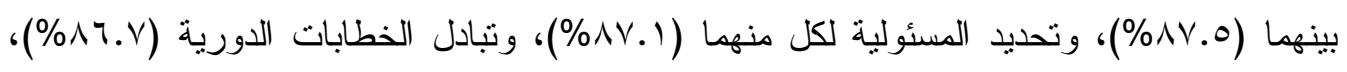

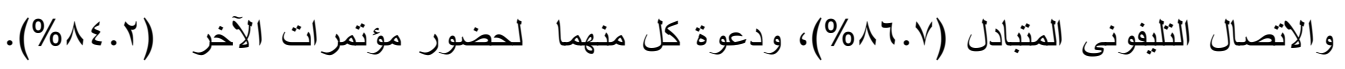
مما قد بساعد على توفير الوقت و الجهد و المال. 
جدول رقم (V): وسائل تقوية العلاقة التكاملية بين الإرشاد الزراعى و التوجيه

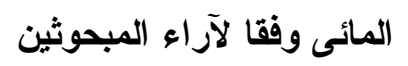

\begin{tabular}{|c|c|c|c|c|c|c|c|c|c|c|c|}
\hline \multirow{3}{*}{$\begin{array}{c}\text { النسبي } \\
\text { \% }\end{array}$} & \multirow{3}{*}{ المتوسطة } & \multicolumn{8}{|c|}{ درجة الأهمية: } & \multirow{3}{*}{ وسائل تقوية العلاقة } & \multirow{3}{*}{ ? } \\
\hline & & \multicolumn{2}{|c|}{ عالية الأهمية } & \multicolumn{2}{|c|}{ متوسطة الأهمية } & \multicolumn{2}{|c|}{ منخفضة الأهمية } & \multicolumn{2}{|c|}{ غير مهمة } & & \\
\hline & & $\%$ & عدد & $\%$ & عدد & $\%$ & عدد & $\%$ & عدد & & \\
\hline $97 . r$ & $r .9$ & 14.7 & or & $11 . \mathrm{V}$ & V & $1 . V$ & 1 & - & - & تنظيم ورش عمل مشتركة & 1 \\
\hline $90 . \xi$ & r.A & 10 & 01 & $11 . \mathrm{V}$ & $\mathrm{v}$ & $r . r$ & $r$ & - & - & توفير اللوائح و الققو انين & $r$ \\
\hline 90.5 & $r . \Lambda$ & Ar.r & 0. & 10 & 9 & $1 . v$ & 1 & - & - & تنظيم حملات توعية & $r$ \\
\hline 9ะ.र & r.A & $\wedge$. & $\varepsilon \wedge$ & 17.2 & 1. & $\begin{array}{r}r . r \\
\end{array}$ & $r$ & - & - & تبادل زيار ات العمل & $\varepsilon$ \\
\hline $9 r . \wedge$ & r.A & vo & $\leq 0$ & ro & 10 & - & - & - & - & تشكيل لجان عمل مشتركة & 0 \\
\hline 94.4 & r.v & VI.V & $\leqslant 7$ & r. & Ir & $r . r$ & $r$ & - & - & مشتركة براد برج تدريية & 7 \\
\hline 94.9 & $r . v$ & VA.r & $\varepsilon V$ & $17 . \mathrm{V}$ & 1. & $r . r$ & $r$ & $1 . V$ & 1 & منع تكرار العمل & v \\
\hline 94.0 & r.v & VI.V & $\leqslant 7$ & 17.7 & 1. & T.V & $\varepsilon$ & - & - & الايمان أن لكل جهة دور & $\wedge$ \\
\hline 9 9.1 & r.v & VI.V & $\leq 7$ & IA.r & 11 & I.V & 1 & r.T & $r$ & تعريف كل جهة بمهام & 9 \\
\hline $91 . \mathrm{V}$ & r.V & vo & $\leqslant 0$ & $11 . r$ & 11 & 。 & $r$ & $1 . V$ & 1 & تالإروير مر اكز للمعلومات & 1. \\
\hline $91 . r$ & r.V & vo & $\leq 0$ & $17 . V$ & 1. & T.V & $\varepsilon$ & $1 . V$ & 1 & وضع خطة نطوير مشتركة & 11 \\
\hline $91 . r$ & r.v & vo & «o & IN.r & 11 & $\begin{array}{r}r . r \\
\end{array}$ & $r$ & r.r & $r$ & إعداد نشر ات إرشادية & Ir \\
\hline $91 . r$ & r.V & v1.v & $\varepsilon r$ & YI.V & $1 \pi$ & 7.V & $\varepsilon$ & - & - & المشترك اجتماعات دورية للعمل & $\pi$ \\
\hline $9 . . \varepsilon$ & $r .1$ & vo & $\leq 0$ & 10 & 9 & $7 . \mathrm{V}$ & $\varepsilon$ & $r . r$ & $r$ & عقد ندوات للعمل المشترك & $1 \varepsilon$ \\
\hline 9. & $r .7$ & Vr.r & $\varepsilon \varepsilon$ & $17 . v$ & 1. & $7 . \mathrm{V}$ & $\varepsilon$ & r.r & $r$ & إقامة مشرو عات مشتركة & 10 \\
\hline$\wedge \Lambda . \wedge$ & $r .1$ & T..V & $\varepsilon$. & rt.r & $1 \varepsilon$ & A.r & o & $1 . \mathrm{V}$ & 1 & نوفير الحوافز المالية & 17 \\
\hline$\wedge \wedge . \wedge$ & $r .1$ & 70 & rq & ro & 10 & 1. & 7 & - & - & تتسيق العمل المشترك & IV \\
\hline AN.r & $r .0$ & 7.. & $\varepsilon$ & ro & 10 & $r . r$ & $r$ & 0 & $r$ & تنظيم لقاءات عمل مشتركة & 11 \\
\hline M..r & $r .0$ & 70 & $r 9$ & $r r . r$ & $1 \varepsilon$ & $11 . \mathrm{V}$ & $v$ & - & - & توفير الامكانيات المالية & 19 \\
\hline$\lambda \vee .9$ & r.0 & 70 & rq & rr.r & $1 \varepsilon$ & 1. & 1 & $1 . V$ & 1 & مشتركة مكاتب اتصال & $r$. \\
\hline NY.O & r.o & 7. & 4 & M.V & 19 & T.V & $\varepsilon$ & $1 . V$ & 1 & التمثيل المتبادل فيما بينهما & rI \\
\hline$\lambda \vee .1$ & $r .0$ & $71 . V$ & $r v$ & rA.r & IV & T.V & $\varepsilon$ & $r . r$ & $r$ & تحديد المسئولية لكل منهما & rr \\
\hline AT.V & $r .0$ & $7 \pi . V$ & $\varepsilon$. & $11 . r$ & 11 & 1. & 7 & o & $r$ & تبينهما الخطابات الدورية & rt \\
\hline A..V & r.o & 70 & $r 9$ & rI.V & 14 & A.r & 0 & 0 & $r$ & الاتصال التليفونى المتبادل & $r \varepsilon$ \\
\hline$\Lambda \varepsilon . Y$ & r.乏 & ON.r & ro & ro & 10 & $11 . \mathrm{V}$ & v & 0 & $r$ & دعؤتمرة كل منهما لحضور & ro \\
\hline
\end{tabular}

\section{التوصيات}

1- ضرورة قيام جهات الاختصاص بوز ارة الزر اعة و استصلاح الاراضي، ووزارة الموارد المائية والري بتغيير الفكر السائد في الوزارتين بأفضلية قطاع على قطاع آخر في العمل 
إلى مفهوم أن كل قطاع له دور هام لا يقل أهمية عن دور القطاع الآخر بالوزارة الأخرى

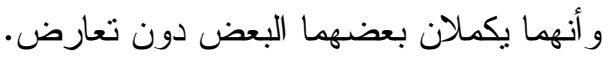

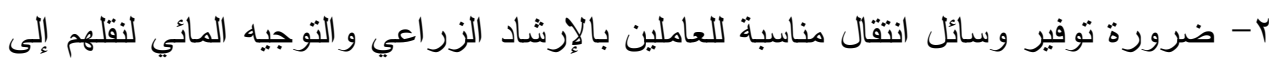
مو اقع مشروعات تطوير الري.، و كذلك توفير وسائل الإتصال المناسبة بينهما.

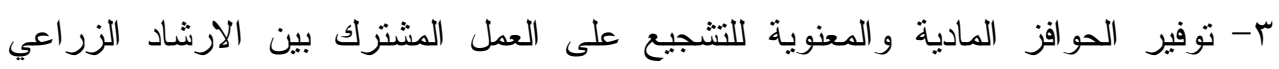
و التوجيه المائي. ع- تفسير ونوفير اللوائح والقو انين المنظمة للعمل المشترك للعاملين بقطاعي الارشاد الزراعي و التوجيه المائي. ه- تشجيع العمل المشترك بين الارشاد الزراعي والتوجيه المائي مثل التنريب المشترك،

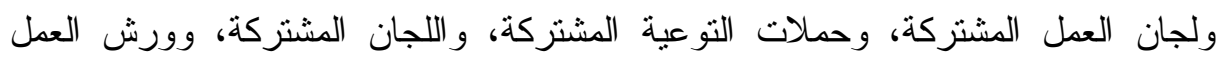
المشتركة، و الإجتماعات و الندو ات المشتركة. ولمات

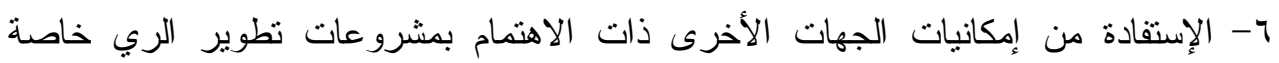

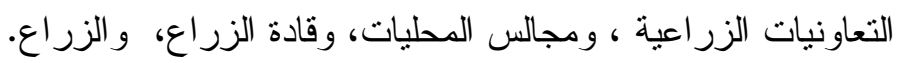
المراجع

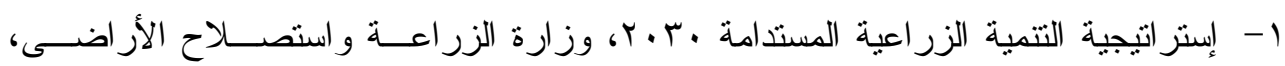

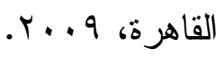

r- الثافعى، عماد مختار ، عبد الحليم عباس قشطة، ترشيد استخدام مياه الرى كأحد مجــالات

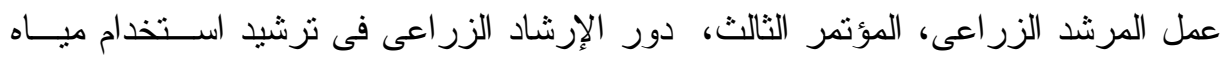

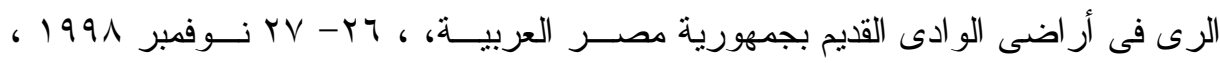

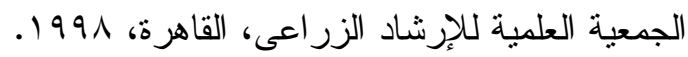

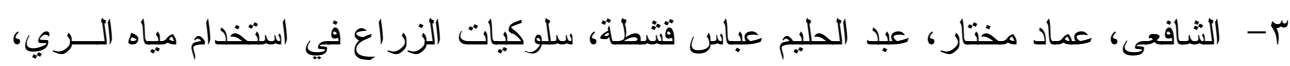

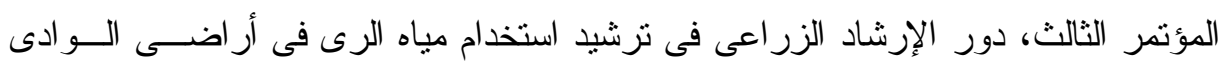

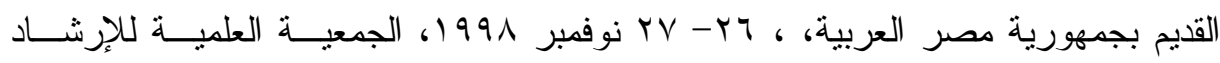

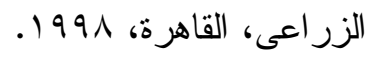
ع - الطنوبي، محمد عمر، الإنتاجية الزر اعية بين البحث العلمي و الإرشــاد الزر اعـي، منشــأة

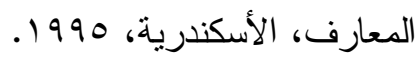

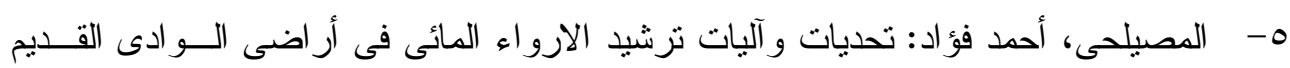

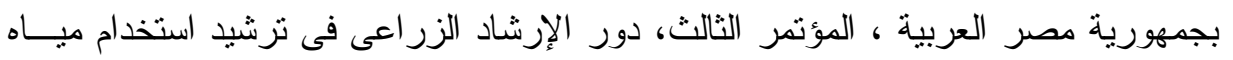

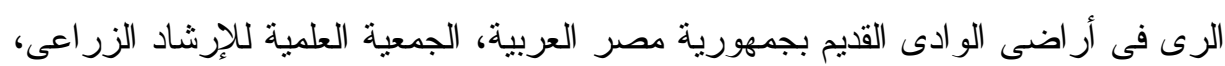
القاهرة، צr- Y Y نوفمبر 1991 ، القاهرة، 1991.

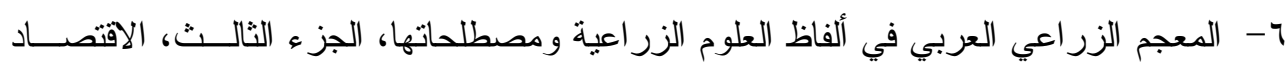
الزر اعي، المجلد الثالث، الارشاد الزر اعي، مطابع الثروق، بيروت، بدون ناريخ،. 
V- شرشر ، حسن على: بعض العو امل المؤثرة لإِ در الك زراع المساقى المطـــورة الإيضــاحية

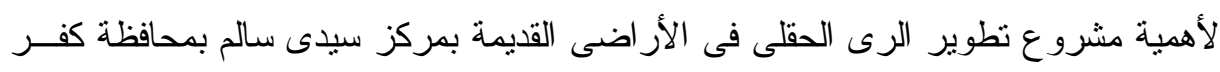

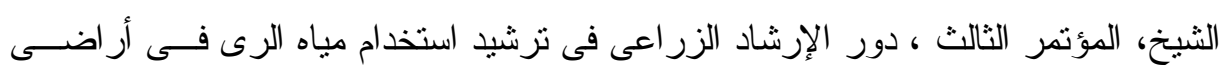

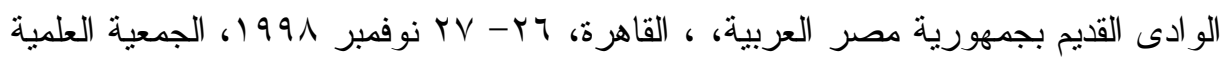

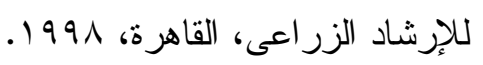

1- رزق، محمد على : ترشيد استهلاك المياه المستخدمة للرى فى الأر اضى القديمة وإمكانيـــة

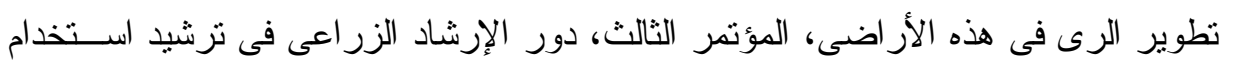

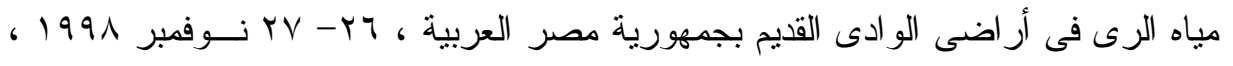

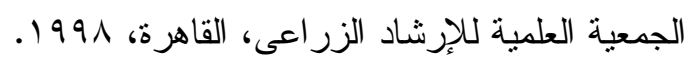

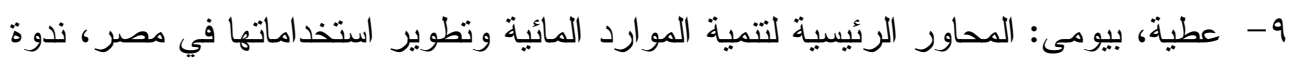
الأمن المائى فى مصر كأحد تحديات التتمية فى المستقبل، مركز الإرشاد و التندريب، كليــة

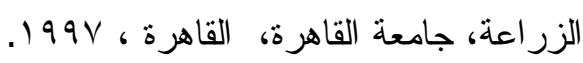

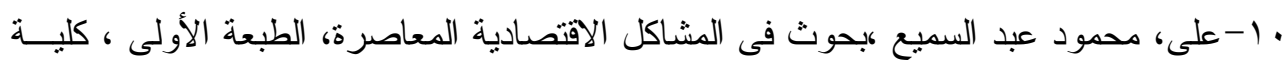

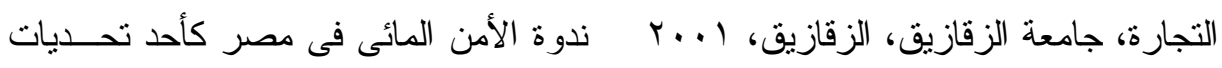

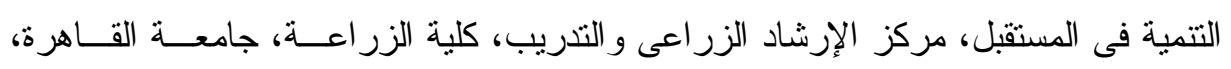

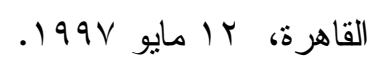

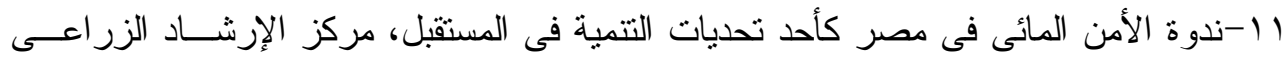

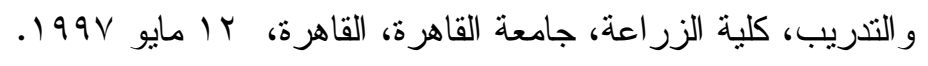

12 - Lawrence, Paul , Jay , W. Lorsch, Differentation and Integration In complex Organizations , Admin, so . quar. June 1967. 


\title{
THE INTEGRATED TASKS OF EXTENSION AND WATER ADVISORY IN THE FIELD OF IRRIGATION DEVELOPMENT PROJECTS FROM POINT OF VIEW OF AGRICULTURAL EXTENSION AND WATER ADVISORY ENGINEERS IN QUENA AND KAFR EL- SHEIKH GOVERNORATS
}

\author{
BADRAN, S. M., A. H. YOUSEF, W. M. ABDUL SADIQ \\ Agricultural Extension and Rural Development Research Institute - ARC, Giza, Egypt \\ (Manuscript received 16 September 2014)
}

\begin{abstract}
The present study aims at identifying the specific roles of both agricultural extension and water advisory in the different stages of irrigation development projects, as well as investigating the possible integration between the two sides; finally the study aims at identifying the most important means to establish the integration between them in this field. This study was conducted in two governorates (Quena and Kafr ElSheikh). Data were collected through personal interview by using a questionnaire from agricultural extension workers and water advisory engineers (35 and 25, respectively) in May and June, 2013. Data were presented by using averages, percentages and frequencies tabulation .
\end{abstract}

The study results can be summarized as following:

- Agricultural extension should focus on awareness stage of the project while water advisory should concern with initial and final planning and implementation stages.

- In monitoring and Evaluation stags both of them implement different tasks.

- Complementary relationship could be established between them according to their capabilities to perfom integrated tasks

- Results of the study revealed also the main problems that prevent from integration due to the absence of the finance to perform joint projects and lack of the needed training.

Finally, the study reached to a set of important recommendations that may help in the establishment of integrated relationships between agricultural extension and water advisory to save time, effort and money. 